( ) ПЕТРОВА Н. В., КОНДРАТЬЕВА Е. И., ПОЛЯКОВ А. В., ИВАЩЕНКО Т. Э., ПАВЛОВ А. Е., ЗИНЧЕНКО Р. А., ГИНТЕР Е. К., ОДИНОКОВА О. Н., НАЗАРЕНКО Л. П., КАПРАНОВ Н. И., АМЕЛИНА Е. Л., СТАРИНОВА М.А., КУЦЕВ С. И., ИЖЕВСКА В. Л., КОНДРАТЕНКО О. В., БОЙЧЕНКО Е. А., КОЗЛОВ А. В., БОЙЦОВА Е. В., ГЕМБИЦКАЯ Т. Е., МОСКВИНА Д. М., СТЕПАНЕНКО Т. А., ФИЛИППОВА Т. А., КОНОВАЛОВА Л. Е., МАХМУТОВА В. Р., ОРЛОВ А. В., ПАШКЕВИЧ А. А., НИКИТИНА М. И., КОВАЛЕВ В. Н., ИГНАТЬЕВА М. Н., УШАТСКАЯ О. А., БОРИСЕНКО Т. С., АНТИПОВА Л. А., ПОНОМАРЕВА Н. Д., ШУЛЯК И. П., НОВИКОВА О. Б., АЛИМОВА И. Л., ВОДОВОЗОВА Э. В., ЛЕДЕНЕВА Л. Н., ЕНИНА Е. А., ПОНОМАРЕВА Т. А., ОГАНЕСЯН И. С., КАНУКОВА Н. А., АЛЕКСАНЯН М. Э., ЗАКУРНАЕВА Е. В., ФИЛИМОНОВА М. Н., СМИРНОВА И. И., МУХАЧЕВА В. В., КАЛИНИНА Ю. Э., БУЛАТОВА И. А., ТРЯСЦЫНА Н. В., СИМАНОВА Т. В., ОСИПОВА Е. В., СТАРОДУБЦЕВА О. И., МУРАЛЕВА Н. П., КОЧЕРГИНА Т. А., ГОГОЛЕВА Е. В., ГУБАРЕВА Т. А., КОЗЛОВА Е. А., СИКОРА Н. В., МОЛЧАНОВА О. В., САЦУК Н. А., РЕВЕЛЬ-МУРОЗ Н. П., КАРИМОВА И. П., ГОЛУБЦОВА О. И., ПАВЛОВ П. И., АШЕРОВА И. К., ЗИЛЬБЕР И. Е.

УДК $575.224,616.062$

DOI: $10.20333 / 2500136-2019-2-47-59$

\title{
ОСОБЕННОСТИ СПЕКТРА ПАТОГЕННЫХ ГЕНЕТИЧЕСКИХ ВАРИАНТОВ ГЕНА CFТR У БОЛЬНЫХ МУКОВИСЦИДОЗОМ ИЗ РОССИЙСКОЙ ФЕДЕРАЦИИ
}

Н. В. Петрова ${ }^{1}$ Е. И. Кондратьева ${ }^{1}$, А. В. Поляков ${ }^{1}$, Т. Э. Иващенко ${ }^{3}$, А. Е. Павлов ${ }^{4}$, Р. А. Зинченко ${ }^{1,5}$, Е. К. Гинтер ${ }^{1}$, О. Н. Одинокова ${ }^{6}$, Л. П. Назаренко ${ }^{6}$, Н. И. Капранов ${ }^{1}$, Е. Л. Амелина ${ }^{2}$ М.А. Старинова ${ }^{1}$, С. И. Куцев ${ }^{1}$, В. Л. Ижевская ${ }^{1}$, О. В. Кондратенко ${ }^{7}$, Е. А. Бойченко ${ }^{8}$, А. В. Козлов ${ }^{7}$ Е. В. Бойцова ${ }^{9}$, Т. Е. Гембицкая ${ }^{10}$, Д. М. Москвина ${ }^{10}$, Т. А. Степаненко ${ }^{11}$, Т. А. Филиппова ${ }^{11}$, Л. Е. Коновалова ${ }^{12}$, В. Р. Махмутова ${ }^{11}$, А. В. Орлов ${ }^{13}$, А. А. Пашкевич ${ }^{13}$, М. И. Никитина ${ }^{13}$, В. Н. Ковалев ${ }^{13}$, М. Н. Игнатьева ${ }^{13}$, О. А. Ушатская ${ }^{13}$, Т. С. Борисенко ${ }^{13}$, Л. А. Антипова ${ }^{13}$, Н. Д. Пономарева $a^{14}$, И. П. Шуляк ${ }^{15}$, О. Б. Новикова ${ }^{16}$, И. Л. Алимова ${ }^{16,17}$, Э. В. Водовозова ${ }^{18}$, Л. Н. Леденева ${ }^{18}$, Е. А. Енина ${ }^{19}$, Т. А. Пономарева ${ }^{18}$, И. С. Оганесян ${ }^{19}$, Н. А. Канукова ${ }^{20}$, М. Э. Алексанян ${ }^{21}$, Е. В. Закурнаева ${ }^{21}$, М. Н. Филимонова ${ }^{6}$, И. И. Смирнова ${ }^{6}$ В. В. Мухачева ${ }^{6}$, Ю. Э. Калинина ${ }^{22}$, И. А. Булатова ${ }^{23}$, Н. В. Трясцына ${ }^{23}$, Т. В. Симанова ${ }^{24}$, Е. В. Осипова ${ }^{25}$, О. И. Стародубцева ${ }^{25}$, Н. П. Муралева ${ }^{24}$, Т. А. Кочергина ${ }^{25}$, Е. В. Гоголева ${ }^{24}$, Т. А. Губарева ${ }^{26}$, Е. А. Козлова ${ }^{27}$, Н. В. Сикора ${ }^{28}$, О. В. Молчанова ${ }^{29}$, Н. А. Сацук ${ }^{30}$ Н. П. Ревель-Муроз ${ }^{31}$, И. П. Каримова ${ }^{32}$, О. И. Голубцова ${ }^{33}$, П. И. Павлов ${ }^{34}$, И. К. Ашерова ${ }^{35}$, И. Е. Зильбер ${ }^{36}$.

${ }^{1}$ Медико-генетический научный центр, Москва 115522, Российская Федерация

${ }^{2}$ Научно-исследовательский институт пульмонологии, Москва 105077, Российская Федерация

${ }^{3}$ Научно-исследовательский институт акушерства, гинекологии и репродуктологии им. Д. О. Отта, Санкт-Петербург 199034,

Российская Федерация

${ }^{4}$ ООО Парсек Лаб, Санкт-Петербург 197350, Российская Федерация

${ }^{5}$ Московский областной научно-исследовательский клинический институт им. М. Ф. Владимирского, Москва 129110, Российская Федерация

${ }^{6}$ Томский национальный исследовательский медицинский центр, Томск 634009, Российская Федерация

${ }^{7}$ Клиника Самарского государственного медицинского университета, Самара 443079, Российская Федерация

${ }^{8}$ Самарская областная детская клиническая больница им. Н. Н. Ивановой, Самара 443079, Российская Федерация

${ }^{9}$ Санкт-Петербургский государственный педиатрический медицинский университет, Санкт-Петербург 194100, Российская Федерация

${ }^{10}$ Первый Санкт-Петербургский государственный медицинский университет им. акад. И. П. Павлова, Санкт-Петербург 197022,

Российская Федерация

${ }^{11}$ Городская многопрофильная больница № 2, Санкт-Петербург 194354, Российская Федерация

${ }^{12}$ Детская клиническая больница, Санкт-Петербург 195009, Российская Федерация

${ }^{13}$ Детская городская больница Святой Ольги, Санкт-Петербург 194156, Российская Федерация

${ }^{14}$ Свердловская областная клиническая больница № 1, Екатеринбург 620102, Российская Федерация

${ }^{15}$ Областная детская клиническая больница № 1, Екатеринбург 620149, Российская Федерация

${ }^{16}$ Смоленский государственный медицинский университет, Смоленск 214019, Российская Федерация

${ }^{17}$ Смоленская областная детская клиническая больница, Смоленск 214019, Российская Федерация

${ }^{18}$ Ставропольский государственный медицинский университет, Ставрополь 355017, Российская Федерация

${ }^{19}$ Краевая детская клиническая больница, Ставрополь 355029, Российская Федерация

${ }^{20}$ Ставропольский краевой клинический консультативно-диагностический центр, Ставрополь 355017, Российская Федерация

${ }^{21}$ Тамбовская областная детская клиническая больница, Тамбов 392000, Российская Федерация

${ }^{22}$ Тульская детская областная клиническая больница, Тула 300010, Российская Федерация

${ }^{23}$ Областная клиническая больница № 1, Тюмень 625023, Российская Федерация

${ }^{24}$ Республиканская детская клиническая больница, Ижевск 426009, Российская Федерация

${ }^{25}$ Первая республиканская клиническая больница, Ижевск 426000, Российская Федерация

${ }^{26}$ Ульяновская областная детская клиническая больница имени политического и общественного деятеля Ю.Ф.Горячева, Ульяновск 432011, Российская Федерация

${ }^{27}$ Детская краевая клиническая больница им. А. К. Пиотровича, Хабаровск 680003, Российская Федерация

${ }^{28}$ Перинатальный центр, Хабаровск 680028, Российская Федерация

${ }^{29}$ Институт повышения квалификации специалистов здравоохранения, Хабаровск 680009, Российская Федерация

${ }^{30}$ Нижневартовская окружная клиническая детская больница, Нижневартовск 628609, Российская Федерация

${ }^{31}$ Челябинская областная клиническая больница, Челябинск 454048, Российская Федерация 
32Челябинская областная детская клиническая больница, Челябинск 454087, Российская Федерация

${ }_{33}^{33}$ Республиканская детская клиническая больница, Чебоксары 428003, Российская Федерация

${ }^{34}$ Республиканская клиническая больница, Чебоксары 428018, Российская Федерация

${ }^{35}$ Детская клиническая больница № 1, Ярославль 150003, Российская Федерация

${ }^{36}$ Клиническая больница № 2, Ярославль 150010, Российская Федерация

Цель исследования. Изучить особенности и разнообразие спектра патогенных генетических вариантов гена CFTR (АВCC7) у российских пациентов с МВ, представленных в Регистре больных муковисцидозом (МВ) Российской Федерации (РФ) 2017г.

Материал и методы. Проанализированы результаты генотипирования, включавшего анализ частых патогенных генетических вариантов, секвенирование кодирующей последовательности, поиск генных перестроек гена CFTR, 3096 больных из 81 региона-субъекта Российской Федерации, представленных в Регистре больных МВ в РФ 2017 г.

Результаты. Выявлено 196 патогенных генетических вариантов гена CFTR. Суммарная доля 11 генетических вариантов c.1521_1523delCTT (F508del), c.54-5940_273+10250del21kb (CFTRdele2,3), c.274G>A (E92K), c.2012delT (2143delT), c.3718-2477C >T (3849+10kbC->T), c.3846G>A (W1282X), c.2052_2053insA (2184insA), c.1545_1546delTA (1677delTA), c.3909C >G (N1303K), c.1624G>T (G542X), c.413_415dupTAC (L138ins) составляет 75,6 \%. 102 редких вариантов обнаружены однократно, 29 - дважды. Как в спектре, так и по частоте у пациентов в РФ преобладают варианты, приводящие к серьезным нарушениям функции белка CFTR (I, II, III классы). 44 генетических варианта не внесены в базы CFTR1 и CFTR2.

Заключение. На основании данных Регистра 2017 года определены спектр и относительные частоты патогенных вариантов последовательности гена CFTR у российских больных MB; описано их распределение в зависимости от класса и типа. Выявлены генетические варианты, ранее не описанные в базах CFTR1 и CFTR2. Полученные результаты могут использоваться для оптимизации генетического консультирования и клинической работы с семьями, отягощенными MB, а также для дальнейших исследований патогенетической значимости ранее не описанных генетических вариантов гена CFTR.

Ключевые слова: муковисцидоз, ген CFTR, спектр патогенных генетических вариантов, российская популяция.

Конфликт интересов. Авторы декларируют отсутствие явных и потенциальных конфликтов интересов, связанных с публикацией настоящей статьи. Для иитирования: Петрова НВ, Кондратьева ЕИ, Поляков АВ, Иващенко ТЭ, Павлов АЕ, Зинченко РА, Гинтер ЕК, Одинокова ОН, Назаренко ЛП, Капранов НИ, Амелина ЕЛ, Старинова МА, Куцев СИ, Ижевска ВЛ, Кондратенко ОВ, Бойченко ЕА, Козлов АВ, Бойцова ЕВ, Гембицкая ТЕ, Москвина ДМ, Степаненко ТА, Филиппова ТА, Коновалова ЛЕ, Махмутова ВР, Орлов АВ, Пашкевич АА, Никитина МИ, Ковалев ВН, Игнатьева МН, Ушатская ОА, Борисенко ТС, Антипова ЛА, Пономарева НД, Шуляк ИП, Новикова ОБ, Алимова ИЛ, Водовозова ЭВ, Леденева ЛН, Енина ЕА, Пономарева ТА, Оганесян ИС, Канукова НА, Алексанян МЭ, Закурнаева ЕВ, Филимонова МН, Смирнова ИИ, Мухачева ВВ, Калинина ЮЭ, Булатова ИА, Трясцына НВ, Симанова ТВ, Осипова ЕВ, Стародубцева ОИ, Муралева НП, Кочергина ТА, Гоголева ЕВ, Губарева ТА, Козлова ЕА, Сикора НВ, Молчанова ОВ, Сацук НА, Ревель-Муроз НП, Каримова ИП, Голубцова ОИ, Павлов ПИ, Ашерова ИК, Зильбер ИЕ. Особенности спектра патогенных генетических вариантов гена CFTR у больных муковисцидозом из Российской Федерации. Сибирское медииинское обозрение. 2019;(2):47-59. DOI: 10.20333/2500136-2019-2-47-59

\section{FEATURES OF SPECTRUM OF PATHOGENIC GENETIC VARIANTS OF THE CFTR GENE IN PATIENTS WITH CYSTIC FIBROSIS FROM THE RUSSIAN FEDERATION}

N. V. Petrova ${ }^{1}$, E. I. Kondratyeva ${ }^{1}$, A. V. Polyakov ${ }^{1}$, T. E. Ivaschenko ${ }^{3}$, A. E. Pavlov, R. A. Zinchenko ${ }^{1,5}$, E. K. Ginter ${ }^{1}$, O. N. Odinokova ${ }^{6}$, L. P. Nazarenko ${ }^{6}$,

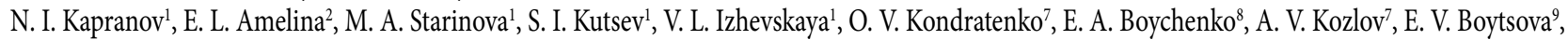
T. E. Gembitskaya ${ }^{10}$, D. M. Moskvina ${ }^{10}$, T. A. Stepanenko ${ }^{11}$, T. A. Filippova ${ }^{11}$, L. E. Konovalova ${ }^{12}$, V. R. Makhmutova ${ }^{11}$, A. V. Orlov ${ }^{13}$, A. A. Pashkevich ${ }^{13}$, M. I. Nikitina ${ }^{13}$, V. N. Kovalev ${ }^{13}$, M. N. Ignatyeva ${ }^{13}$, O. A. Ushatskaya ${ }^{13}$, T. S. Borisenko ${ }^{13}$, L. A. Antipova ${ }^{13}$, N. D. Ponomareva ${ }^{13}$, I. P. Shulyak ${ }^{15}$, O. B. Novikova ${ }^{16}$, I. L. Alimova ${ }^{16,17}$, E. V. Vodovozova ${ }^{18}$, L. N. Ledeneva ${ }^{18}$, E. A. Yenina ${ }^{19}$, T. A. Ponomareva ${ }^{18}$, I. S. Oganesyan ${ }^{19}$, N. A. Kanukova ${ }^{20}$, M. E. Aleksanyan ${ }^{21}$, E. V. Zakurnaeva ${ }^{21}$, M. N. Filimonova ${ }^{6}$, I. I. Smirnova ${ }^{6}$, V. V. Mukhacheva ${ }^{6}$, Yu. E. Kalinina ${ }^{22}$, I. A. Bulatova ${ }^{23}$, N. V. Tryastsina ${ }^{23}$, T. V. Simanova ${ }^{24}$, E. V. Osipova ${ }^{25}$, O. I. Starodubtseva ${ }^{25}$, N. P. Muraleva ${ }^{24}$, T. A. Kochergina ${ }^{25}$, E. V. Gogoleva ${ }^{24}$, T. A. Gubareva ${ }^{26}$, E. A. Kozlova ${ }^{27}$, N. V. Sikora ${ }^{28}$, O. V. Molchanova ${ }^{29}$, N. A. Satsuk ${ }^{30}$, N. P. Revel-Muroz ${ }^{31}$, I. P. Karimova ${ }^{32}$, O. I. Golubtsova ${ }^{33}$, P. I. Pavlov ${ }^{34}$, I. K. Asherova ${ }^{35}$, I. E. Zilber ${ }^{36}$. ${ }^{1}$ Research Center for Medical Genetics, Moscow 115522, Russian Federation

${ }^{2}$ Research Institute of Pulmonology, Moscow 105077, Russian Federation

${ }^{3}$ Research Institute of Obstetrics, Gynecology and Reproductive Medicine them. D.O. Ott, St. Petersburg 199034, Russian Federation

${ }^{4}$ Parseq Lab, St. Petersburg 197350, Russian Federation

${ }^{5}$ Moscow Regional Research and Clinical Institute, Moscow 129110, Russian Federation

${ }^{6}$ Tomsk National Research Medical Center, Tomsk 634009, Russian Federation

${ }^{7}$ Clinics of Samara State Medical University, Samara, 443079, Russian Federation

${ }^{8}$ Samara City Cchildren’s Clinical Hospital № 1 named after N. N. Ivanova, Samara 443079, Russian Federation

${ }^{9}$ St. Petersburg State Pediatric Medical University, St. Petersburg 194100, Russian Federation

${ }^{10}$ Pavlov First Saint Petersburg State Medical University, St. Petersburg 197022, Russian Federation

${ }^{11}$ City General Hospital №2, St. Petersburg 194354, Russian Federation

${ }^{12}$ Children's Clinical Hospital, St. Petersburg 195009, Russian Federation

${ }^{13}$ Children's City Hospital of St. Olga, St. Petersburg 194156, Russian Federation

${ }^{14}$ Sverdlovsk Regional Clinical Hospital № 1, Yekaterinburg 620102, Russian Federation 


\footnotetext{
${ }^{15}$ Regional Children’s Clinical Hospital № 1, Yekaterinburg 620149, Russian Federation

${ }^{16}$ Smolensk State Medical University, Smolensk 214019, Russian Federation

${ }^{17}$ Smolensk Regional Children's Clinical Hospital, Smolensk 214019, Russian Federation

${ }^{18}$ Stavropol State Medical University, Stavropol 355017, Russian Federation

${ }^{19}$ Regional Children's Clinical Hospital, Stavropol 355029, Russian Federation

${ }^{20}$ Stavropol Regional Clinical Consulting and Diagnostic Center, Stavropol 355017, Russian Federation

${ }^{21}$ Tambov Regional Children's Clinical Hospital, Tambov 392000, Russian Federation

${ }^{22}$ Tula Regional Children's Clinical Hospital, Tula 300010, Russian Federation

${ }^{23}$ Regional Clinical Hospital № 1, Tyumen 625023, Russian Federation

${ }^{24}$ Republican Children's Clinical Hospital, Izhevsk 426009, Russian Federation

${ }^{25}$ First Republican Clinical Hospital, Izhevsk 426000, Russian Federation

${ }^{26}$ Goryachev Ulyanovsk Regional Children's Clinical Hospital, Ulyanovsk 432011, Russian Federation

${ }^{27}$ Piotrovich Children's Regional Clinical Hospital, Khabarovsk 680003, Russian Federation

${ }^{28}$ Perinatal Center, Khabarovsk 680028, Russian Federation

${ }^{29}$ Institute for Advanced Studies of Health Professionals, Khabarovsk 680009, Russian Federation

${ }^{30}$ Nizhnevartovsk Regional Clinical Children's Hospital, Nizhnevartovsk 628609, Russian Federation

${ }^{31}$ Chelyabinsk Regional Clinical Hospital, Chelyabinsk 454048, Russian Federation

${ }^{32}$ Chelyabinsk Regional Children’s Clinical Hospital, Chelyabinsk 454087, Russian Federation

${ }^{33}$ Republican Children's Clinical Hospital, Cheboksary 428003, Russian Federation

${ }^{34}$ Republican Clinical Hospital, Cheboksary 428018, Russian Federation

${ }^{35}$ Children’s Clinical Hospital № 1, Yaroslavl 150003, Russian Federation

${ }^{36}$ Clinical Hospital № 2, Yaroslavl 150010, Russian Federation
}

The aim of the research is to study features and diversity of spectrum of pathogenic genetic variants of CFTR gene (ABCC7) in Russian patients with CF presented in the Registry of patients with cystic fibrosis (CF) from the Russian Federation (RF) for 2017.

Material and methods. The following data has been analysed: results of genotyping, including the analysis of frequent pathogenic genetic variants; sequencing of coding order; search for gene rearrangements of CFTR gene; 3096 patients from 81 regions of the Russian Federation represented in the Register of CF patients in the Russian Federation for 2017.

Results. 196 pathogenic genetic variants of CFTR gene were identified. The total share of 11 genetic variants c.1521_1523delCTT (F508del), c.54-5940_273 + 10250del21kb (CFTRdele2,3), c.274G> A (E92K), c.2012delT (2143delT), c.3718-2477C> T (3849 + 10kbC-> T), c.3846G> A (W1282X), c.2052_2053insA (2184insA), c.1545_1546delTA (1677delTA), c.3909C > G (N1303K), c.1624G> T (G542X), c. 413_415dupTAC (L138ins) is 75.6\%. 102 rare variants were found once, 29 - twice. In patients from the Russian Federation, both in spectrum and in frequency, variants, leading to serious dysfunction of the CFTR protein function (classes I, II, III) prevail. 44 genetic variants are not included in the CFTR1 and CFTR2 databases.

Conclusion. Spectrum and relative frequencies of pathogenic variants of CFTR gene sequence in Russian CF patients were determined on the basis of Register data for 2017; their distribution depending on class and type was described. Genetic variants that were not previously described in CFTR1 and CFTR2 bases have been identified. The obtained results can be used to optimize genetic consultations and clinical work with families burdened with CF, as well as for further research on pathogenetic significance of genetic variants of CFTR gene that were not previously described.

Key words: cystic fibrosis, CFTR gene, spectrum of pathogenic genetic variants, Russian population.

Conflict of interest. The authors declare the absence of obvious and potential conflicts of interest associated with the publication of this article.

Citation: Petrova NV, Kondratyeva E I, Polyakov AV, Ivaschenko TE, Pavlov AE, Zinchenko RA, Ginter EK, Odinokova ON, Nazarenko LP, Kapranov NI, Amelina EL, Starinova MA, Kutsev SI, Izhevskaya VL, Kondratenko OV, Boychenko EA, Kozlov AV, Boytsova EV, Gembitskaya TE, Moskvina DM, Stepanenko TA, Filippova TA, Konovalova LE, Makhmutova VR, Orlov AV, Pashkevich AA, Nikitina MI, Kovalev VN, Ignatyeva MN, Ushatskaya OA, Borisenko TS, Antipova LA, Ponomareva ND, Shulyak IP, Novikova OB, Alimova IL, Vodovozova EV, Ledeneva LN, Yenina EA, Ponomareva TA, Oganesyan IS, Kanukova NA, Aleksanyan ME, Zakurnaeva EV, Filimonova MN, Smirnova II, Mukhacheva VV, Kalinina YuE, Bulatova IA, Tryastsina NV, Simanova TV, Osipova EV, Starodubtseva OI, Muraleva NP, Kochergina TA, Gogoleva EV, Gubareva TA, Kozlova EA, Sikora NV, Molchanova OV, Satsuk NA, Revel-Muroz NP, Karimova IP, Golubtsova OI, Pavlov PI, Asherova IK, Zilber IE. Features of spectrum of pathogenic genetic variants of the CFTR gene in patients with cystic fibrosis from the Russian Federation. Siberian Medical Review.2019;(2):47-59. DOI: 10.20333/2500136-2019-2-47-59

\section{Введение}

Муковисцидоз (МВ) - частое моногенное заболевание, обусловленное патогенными генетическими вариантами гена CFTR (ABCC7). Ген CFTR содержит 27 экзонов и расположен в регионе 31.1 длинного плеча 7-й хромосомы (7q31.1). МВ характеризуется широкой вариабельностью клинических проявлений, в наибольшей степени являющихся следствием многообразия генетических вариантов гена CFTR [1]. На сегодняшний день описано более 2200 вариантов последовательности гена CFTR, как патогенных, так и с неясной клинической значимостью, а также не имеющих клинических последствий $[2,3]$. Спектр и частота вариантов последовательности гена CFTR значительно различаются в разных странах и этнических группах, что предполагает определенные трудности для разработки региональных протоколов молекулярной диагностики и внедрения достижений таргетной терапии при лечении больных $\mathrm{MB}[4]$. 
Значительные достижения в развитии методов и технологий молекулярно-генетического тестирования позволяют в большинстве случаев успешно осуществлять молекулярно-генетическую диагностику MB. Наибольшую трудность представляет оценка функциональной значимости редких и ранее не идентифицированных генетических вариантов [1].

По состоянию на 31 августа 2018 года на веб-сайте международного проекта CFTR2 [2] представлено 334 патогенных вариантов гена CFTR. Они приводят к нарушению синтеза белка CFTR, транспорта его к апикальной мембране клетки или нарушают его функцию в качестве канала анионов хлора, снижая стабильность или количество молекул белка. В зависимости от влияния на функцию белка CFTR мутации подразделяют на 6 основных классов [5]. В ряде случаях класс генетических вариантов не определен. Генетические варианты I, II и III классов приводят к полному или почти полному прекращению функции хлорного канала, и относятся к «тяжелым», тогда как при вариантах IV-VI классов сохраняется остаточная функция хлорного канала, что позволяет их объединить в группу «мягких» вариантов. «Тяжесть» генетического варианта определяет степень нарушения внешнесекреторной функции поджелудочной железы. «Мягкие» варианты доминируют над «тяжелыми» в отношении панкреатического фенотипа [5].

Целью настоящего исследования является изучение особенностей и разнообразия спектра патогенных генетических вариантов гена CFTR у российских пациентов с MB, внесенных в Регистр больных MB в РФ 2017 г.

\section{Материал и методы}

Материалом исследования являлись данные Регистра больных МВ в РФ 2017 года. В Регистр включены данные о 3096 больных из 81 региона-субъекта Российской Федерации: 3047 живых и 49 умерших. Материалом исследования являлась ДНК больных MB. Проект Регистр больных муковисцидозом Российской Федерации одобрен Комитетом по Этике ФГБНУ «МГНЦ» 20 декабря 2012 года (председатель Этического комитета - проф. Л. Ф. Курило) и пациенты с муковисцидозом и/или их представители подписывали информированное согласие.

Молекулярно-генетическое тестирование проведено согласно алгоритму консенсуса «Муковисцидоз: определение, диагностические критерии, терапия», раздел «Генетика муковисцидоза. Молекулярно-генетическая диагностика при муковисцидозе» [6]. При генетическом исследовании частых генетических вариантов гена CFTR использовалась методика мультиплексной амплификации для выявления инсерционно/делеционных вариантов, для регистрации точковых нуклеотидных замен - метод аллель-специфичного лигирования с последующей амплификацией или метод рестрикционного анализа. Части больных проведено исследование нуклеотидной последовательности кодирующей области гена CFTR методом прямого автоматического секвенирования по Сенгеру на приборе фирмы Applied Biosystems coгласно протоколу фирмы-производителя, либо методом параллельного массового секвенирования (NGS) с последующим подтверждением выявленных изменений секвенированием по Сенгеру. Анализ протяженных перестроек гена CFTR проводили методом количественной MLPA (мультиплексной лигазо-зависимой амплификации проб).

Оценку патогенности генетических вариантов гена CFTR проводили согласно руководству по интерпретации данных генетических вариантов $[7,8]$.

\section{Результаты и обсуждение}

В Регистре 2017 г. приведены сведения о 3096 больных МВ из РФ. Средний возраст - 12,1 9,4 лет. Средний возраст установления диагноза - 3,1 $\pm 6,1$ года. $47,8 \%$ пациентов диагноз установлен в результате неонатального скрининга на МВ.

Молекулярно-генетическое исследование проведено 92,4 \% больным. Общая доля идентифицированных мутантных аллелей составила 88,3 \%. Оба патогенных аллеля были определены у 80,2 \% больных, которым проводилось генетическое исследование, один - у 16,1 \%, у 3,7 \% больных оба мутантных аллеля не идентифицированы.

Всего выявлено 196 патогенных генетических вариантов гена CFTR. Помимо частых выявлено значительное количество редких вариантов: 102 обнаружены однократно, 29 - дважды в выборке исследованных пациентов. Относительные частоты генетических вариантов гена CFTR среди больных MB в порядке убывания представлены в таблице 1.

Среди 196 выявленных генетических вариантов гена CFTR преобладют миссенс-мутации - 32,14 \%, значительную долю составляют делеции/инсерции со сдвигом рамки считывания - 20,41\%; нонсенс-мутации - 21,94 \% и нарушение сплайсинга - 16,84 \%; Делеции/инсерции без сдвига рамки считывания (2,04 \%) и промоторные мутации $(0,5 \%)$ - относительно редки (табл. 2). Обширные перестройки (CVS) составляют 6,12 \%. Следует отметить, что по сравнению с мировыми данными, представленными в проекте CFTR1 [2], разнообразие миссенс-мутаций у российских больных существенно ниже, а нонсенс-мутаций и обширных перестроек - выше, чем в общемировой выборке (табл. 2).

Из выявленных генетических вариантов, класс которых определен, 75,9 \% (110) относятся к I классу, 3,4 \% (5) - ко II, 4,1 \% (6) - III, 6,9 \% (10) - к IV, 6,9 \% (10) - к V и 2,8 \% (4) - к VI классу (табл.1). Таким образом, в спектре выявленных генетических вариантов в РФ преобладают варианты, приводящие к серьезным нарушениям функции белка CFTR (I, II, III классы). «Мягкий» генотип (при котором больной является носителем, по крайней мере, одного варианта IV, V или VI класса) выявлен у 22,0 \% больных. 
Патогенные генетические варианты гена СFTR у больных муковисиидозом из РФ

Pathogenic genetic variants of CFTR gene in patients from the Russian Federation with cystic fibrosis

\begin{tabular}{|c|c|c|c|c|c|c|c|}
\hline № & Название по cDNA & $\begin{array}{l}\text { Название по положению } \\
\text { в белке }\end{array}$ & $\begin{array}{l}\text { Традиционное } \\
\text { название }\end{array}$ & Класс & $\begin{array}{c}\text { Характер нарушения } \\
\text { функции белка }\end{array}$ & $\begin{array}{l}\text { Классификация } \\
\text { в базе CFTR2 [9] }\end{array}$ & $\begin{array}{l}\text { Частота } \\
(\%)\end{array}$ \\
\hline 1 & c.1521_1523delCTT & p.Phe508del & F508del & II & тяжелый & патогенный & 52,8 \\
\hline 2 & c.54-5940_273+10250del21kb & p.Ser18ArgfsX16 & CFTRdele2,3 & I & тяжелый & патогенный & 6,2 \\
\hline 3 & c. $274 G>A$ & p.Glu92Lys & E92K & IV(?) & мягкий & патогенный & 3,0 \\
\hline 4 & c.2012delT & p.Leu671X & 2143delT & I & тяжелый & патогенный & 2,1 \\
\hline 5 & c.3718-2477C>T & нет & $3849+10 k b C->T$ & V & мягкий & патогенный & 2,0 \\
\hline 6 & c. $3846 G>A$ & p.Trp1282X & W1282X & I & тяжелый & патогенный & 1,9 \\
\hline 7 & c.2052_2053insA & p.Gln685ThrfsX4 & 2184insA & I & тяжелый & патогенный & 1,8 \\
\hline 8 & c.1545_1546delTA & p.Tyr515X & 1677delTA & 1 & тяжелый & патогенный & 1,8 \\
\hline 9 & c. $3909 C>G$ & p.Asn1303Lys & N1303K & II & тяжелый & патогенный & 1,5 \\
\hline 10 & c. $1624 G>T$ & p.Gly542X & G542X & I & тяжелый & патогенный & 1,3 \\
\hline 11 & c.413_415dupTAC & p.Leu138dup & L138ins & IV & мягкий & патогенный & 1,2 \\
\hline 12 & c.262_263delTT & p.Leu88llefsX22 & 394delTT & I & тяжелый & патогенный & 0,9 \\
\hline 13 & c. $1000 \mathrm{C}>\mathrm{T}$ & p.Arg334Trp & R334W & IV & мягкий & патогенный & 0,8 \\
\hline 14 & c. $3844 \mathrm{~T}>\mathrm{C}$ & p.Trp1282Arg & W1282R & II & тяжелый & не описан & 0,6 \\
\hline 15 & c. $1397 \mathrm{C}>\mathrm{G}$ & p.Ser466X & S466X & I & тяжелый & патогенный & 0,5 \\
\hline 16 & c. $2657+5 G>A$ & нет & $2789+5 G>A$ & V & мягкий & патогенный & 0,5 \\
\hline 17 & c. $3587 C>G$ & p.Ser1196X & S1196X & I & тяжелый & патогенный & 0,5 \\
\hline 18 & c.3691delT & p.Ser1231ProfsX4 & 3821delT & 1 & тяжелый & патогенный & 0,5 \\
\hline 19 & c.1240_1244delCAAAA & p.Asn415X & 1367 del5 & 1 & тяжелый & не описан & 0,3 \\
\hline 20 & c. $3140-16 \mathrm{~T}>\mathrm{A}$ & нет & $3272-16 \mathrm{~T}>\mathrm{A} \#$ & $\mathrm{~V}$ & мягкий & не описан & 0,3 \\
\hline 21 & c.3196C>T & p.Arg1066Cys & $\mathrm{R} 1066 \mathrm{C}$ & II & тяжелый & патогенный & 0,3 \\
\hline 22 & c.3816_3817delGT & p.Ser1273LeufsX28 & 3944delGT & I & тяжелый & не описан & 0,3 \\
\hline 23 & c. $3929 G>A$ & p.Trp1310X & W1310X & 1 & тяжелый & не описан & 0,2 \\
\hline 24 & c. $2353 \mathrm{C}>\mathrm{T}$ & p.Arg785X & R785X & I & тяжелый & патогенный & 0,2 \\
\hline 25 & c. $1657 C>T$ & p.Arg553X & R553X & 1 & тяжелый & патогенный & 0,2 \\
\hline 26 & c. $3484 C>T$ & p.Arg1162X & R1162X & I & тяжелый & патогенный & 0,2 \\
\hline 27 & c. $4004 \mathrm{~T}>\mathrm{C}$ & p.Leu1335Pro & L1335P & IV & мягкий & патогенный & 0,2 \\
\hline 28 & $c .489+1 G>T$ & нет & $621+1 G->T$ & 1 & тяжелый & патогенный & 0,2 \\
\hline 29 & c. $580-1 \mathrm{G}>\mathrm{T}$ & нет & 712-1G->T & 1 & тяжелый & патогенный & 0,2 \\
\hline 30 & c. $1766+1 \mathrm{G}>\mathrm{A}$ & нет & $1898+1 G->A$ & $I$ & тяжелый & патогенный & 0,1 \\
\hline 31 & c.3883delA & p.lle1295PhefsX33 & 4015delA & I & тяжелый & патогенный & 0,1 \\
\hline 32 & c.(743+1_744-1)_(1584+1_1585-1)dup & нет & CFTRdup6b-10^ & I & тяжелый & патогенный & 0,1 \\
\hline 33 & c. $1766+1 G>C$ & нет & $1898+1 G->C$ & I & тяжелый & патогенный & 0,1 \\
\hline 34 & c. $3476 \mathrm{C}>\mathrm{T}$ & p.Ser1159Phe & S1159F & неизвестно & мягкий & патогенный & 0,1 \\
\hline 35 & c. $3717 G>A$ & p.Arg1239Arg & $3849 G->A$ & неизвестно & мягкий & патогенный & 0,1 \\
\hline 36 & c.1040G>C & p.Arg347Pro & R347P & IV & мягкий & патогенный & 0,1 \\
\hline 37 & c. $252 \mathrm{~T}>\mathrm{A \#}$ & p.Tyr84X & & 1 & тяжелый & не описан & 0,1 \\
\hline 38 & c. $254 \mathrm{G}>\mathrm{A}$ & p.Gly85Glu & G85E & II & тяжелый & патогенный & 0,1 \\
\hline 39 & c. $2834 \mathrm{C}>\mathrm{T}$ & p.Ser945Leu & S945L & IV & мягкийй & патогенный & 0,1 \\
\hline 40 & c. $3454 G>C$ & p.Asp1152His & $\mathrm{D} 1152 \mathrm{H}$ & IV & мягкий & $\begin{array}{c}\text { варьирующие } \\
\text { клинические } \\
\text { проявления } \\
\end{array}$ & 0,1 \\
\hline 41 & c. $3472 \mathrm{C}>\mathrm{T}$ & p.Arg1158X & R1158X & 1 & тяжелый & патогенный & 0,1 \\
\hline 42 & c. $349 \mathrm{C}>\mathrm{T}$ & p.Arg117Cys & $\mathrm{R} 117 \mathrm{C}$ & IV & мягкий & патогенный & 0,1 \\
\hline 43 & c.3528delC & p.Lys1177SerfsX15 & 3659delC & I & тяжелый & патогенный & 0,1 \\
\hline 44 & c. $1766+2 T>C$ & нет & c. $1766+2 T>C$ & 1 & тяжелый & не описан & 0,1 \\
\hline 45 & c. $1116+1 G>A$ & нет & $1248+1 G->A$ & I & тяжелый & патогенный & 0,1 \\
\hline 46 & c. $2374 C>T$ & p.Arg792X & R792X & I & тяжелый & патогенный & 0,1 \\
\hline 47 & c. $287 \mathrm{C}>\mathrm{A}$ & p.Ala96Glu & A96E & неизвестно & мягкий & не описан & 0,1 \\
\hline 48 & c.3475T>C & p.Ser1159Pro & S1159P & неизвестно & мягкий & патогенный & 0,1 \\
\hline 49 & c.3889dupT & p.Ser1297PhefsX5 & 4016insT & I & тяжелый & патогенный & 0,1 \\
\hline 50 & c.4251delA & p.Glu1418ArgfsX14 & 4382delA & $\mathrm{VI}$ & мягкий & патогенный & 0,1 \\
\hline 51 & c. $4364 C>G$ & p.Ser1455Ter & S1455X & $\mathrm{VI}$ & мягкий & патогенный & 0,1 \\
\hline 52 & c.(743+1_744-1)_(1116+1_1117-1)dup & нет & CFTRdup6b,7* & I & тяжелый & патогенный & 0,1 \\
\hline 53 & c. $1584+1 G>A$ & нет & $1716+1 G->A$ & I & тяжелый & патогенный & 0,1 \\
\hline 54 & c. $1585-1 \mathrm{G}>\mathrm{A}$ & нет & 1717-1G->A & 1 & тяжелый & патогенный & 0,1 \\
\hline 55 & c. $1705 T>C$ & p.Tyr569His & $\mathrm{Y} 569 \mathrm{H}$ & неизвестно & мягкий & не описан & 0,1 \\
\hline
\end{tabular}




\begin{tabular}{|c|c|c|c|c|c|c|c|}
\hline 56 & c.1735G>T & p.Asp579Tyr & D579Y & неизвестно & тяжелый & не описан & 0,1 \\
\hline 57 & $c .223 C>T$ & p.Arg75X & $R 75 X$ & $T$ & тяжелый & патогенный & 0,1 \\
\hline 58 & c.1127_1128insA & p.GIn378AlafsX4 & 1259insA & $\mathrm{I}$ & тяжелый & патогенный & 0,1 \\
\hline 59 & c. $293 \mathrm{~A}>\mathrm{G}$ & p.GIn98Arg & Q98R & неизвестно & мягкий & патогенный & 0,1 \\
\hline 60 & c.3107C>A\# & p.Thr1036Asn & & неизвестно & мягкий & не описан & 0,1 \\
\hline 61 & $c .328 \mathrm{G}>\mathrm{C}$ & p.Asp110His & $\mathrm{D} 110 \mathrm{H}$ & неизвестно & мягкий & патогенный & 0,1 \\
\hline 62 & c.3535_3536insTCAA & p.Thr1179llefsX17 & 3667ins4 & I & тяжелый & патогенный & 0,1 \\
\hline 63 & c.43delC & p.Leu15PhefsX10 & 175delC & $T$ & тяжелый & патогенный & 0,1 \\
\hline 64 & c.442delA & p.lle148LeufsX5 & 574delA & 1 & тяжелый & патогенный & 0,1 \\
\hline 65 & c.472dupA & p.Ser158LysfsX5 & 604insA & 1 & тяжелый & не описан & 0,1 \\
\hline 66 & c.(273+1_274-1)_(1679+1_1680-1)del & нет & CFTRdele4-10^ & 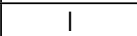 & тяжелый & патогенный & 0,04 \\
\hline 67 & c.1083G>A\# & p.Trp361X & & 1 & тяжелый & не описан & 0,04 \\
\hline 68 & c.1209G>C & p.Glu403Asp & E403D & неизвестно & тяжелый & не описан & 0,04 \\
\hline 69 & c.1219delG\# & p.Glu407AsnfsX35 & & 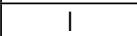 & тяжелый & не описан & 0,04 \\
\hline 70 & c.1262delC\# & p.Thr421llefsX21 & & 1 & тяжелый & не описан & 0,04 \\
\hline 71 & c. $1652 \mathrm{G}>\mathrm{A}$ & p.Gly551Asp & G551D & III & тяжелый & патогенный & 0,04 \\
\hline 72 & c.174_177delTAGA & p.Asp58GlufsX32 & & $T$ & тяжелый & патогенный & 0,04 \\
\hline 73 & c.1911delG & p.Gln637HisfsX26 & 2043delG & 1 & тяжелый & не описан & 0,04 \\
\hline 74 & c.2051_2052delAAinsG & p.Lys684SerfsX38 & $2183 A A->G$ & 1 & тяжелый & патогенный & 0,04 \\
\hline 75 & c.2052delA & p.Lys684AsnfsX38 & 2184delA & 1 & тяжелый & патогенный & 0,04 \\
\hline 76 & $c .2128 \mathrm{~A}>T$ & p.Lys710X & K710X & $\mathrm{I}$ & тяжелый & патогенный & 0,04 \\
\hline 77 & c.2589_2599delAATTTGGTGCT & p.lle864SerfsX28 & 2721del11 & I & тяжелый & патогенный & 0,04 \\
\hline 78 & c. $2988+1 G>A$ & нет & $3120+1 G->A$ & I & тяжелый & патогенный & 0,04 \\
\hline 79 & c. $3140-26 A>G$ & нет & $3272-26 A->G$ & V & мягкий & патогенный & 0,04 \\
\hline 80 & c. $3209 \mathrm{G}>\mathrm{A}$ & p.Arg1070GIn & R1070Q & IV & мягкий & $\begin{array}{c}\text { варьирующие } \\
\text { клинические } \\
\text { проявления }\end{array}$ & 0,04 \\
\hline 81 & c.3274T $>C$ & p.Tyr1092His & Y1092H & неизвестно & неизвестно & не описан & 0,04 \\
\hline 82 & c.3325delA\# & p.lle1109SerfsX12 & & 1 & тяжелый & не описан & 0,04 \\
\hline 83 & c. $350 \mathrm{G}>\mathrm{A}$ & p.Arg117His & $\mathrm{R} 117 \mathrm{H}$ & IV & мягкий & $\begin{array}{c}\text { варьирующие } \\
\text { клинические } \\
\text { проявления }\end{array}$ & 0,04 \\
\hline 84 & c. $422 \mathrm{C}>\mathrm{A}$ & p.Ala141Asp & A141D & неизвестно & мягкий & патогенный & 0,04 \\
\hline 85 & c.4296_4297insGA & p.Ser1435GlyfsX14 & 4428insGA & $\mathrm{VI}$ & мягкий & патогенный & 0,04 \\
\hline 86 & c. $53+1 \mathrm{G}>\mathrm{T}$ & нет & $185+1 G->T$ & I & тяжелый & патогенный & 0,04 \\
\hline 87 & c.550delC & p.Leu184PhefsX5 & 681delC & I & тяжелый & не описан & 0,04 \\
\hline 88 & c.869+2T->G\# & нет & & I & тяжелый & не описан & 0,04 \\
\hline 89 & c.1086T>G; c.1086T>A & p.Tyr362X & Y362X & I & тяжелый & не описан & 0,04 \\
\hline 90 & c. $2978 \mathrm{~A}>\mathrm{C} \#$ & p.Asp993Ala & & неизвестно & мягкий & не описан & 0,04 \\
\hline 91 & c. $831 \mathrm{G}>\mathrm{A \#}$ & p.Trp277X & & I & тяжелый & не описан & 0,04 \\
\hline 92 & c. $1525 \mathrm{G}>\mathrm{C} \#$ & p.Gly509Arg & & неизвестно & неизвестно & не описан & 0,04 \\
\hline 93 & c.580G>A\# & p.Gly194Arg & G194R & неизвестно & неизвестно & не описан & 0,04 \\
\hline 94 & c.(?-1)_(1584+1_1585-1)del\# & нет & CFTRdele1-10^ $^{\wedge}$ & I & тяжелый & патогенный & 0,04 \\
\hline 95 & c.(53+1_54-1)_(164+1_165-1)del & нет & CFTRdele2^ $^{\wedge}$ & 1 & тяжелый & патогенный & \\
\hline 96 & c. $[1075 C>A ; 1079 C>A]$ & p.[Gln359Lys;Thr360Lys] & Q359K/T360K & неизвестно & тяжелый & патогенный & \\
\hline 97 & c.[1210-12[5];1210-34TG[12]] & нет е & 5T;TG12 & V & мягкий & $\begin{array}{c}\text { варьирующие } \\
\text { клинические } \\
\text { проявления } \\
\end{array}$ & \\
\hline 98 & c. $1040 \mathrm{G}>\mathrm{A}$ & p.Arg347His & $\mathrm{R} 347 \mathrm{H}$ & IV & мягкий & патогенный & \\
\hline 99 & $c .115 \mathrm{C}>\mathrm{T}$ & p.Gln $39 X$ & Q39X & I & тяжелый & патогенный & \\
\hline 100 & c. $1163 C>T$ & p.Thr388Met & T388M & неизвестно & мягкий & не описан & \\
\hline 101 & c.1202G>A или с. $1203 G>A^{*}$ & p.Trp401X & W401X & I & тяжелый & патогенный & \\
\hline 102 & c. $1210-12[5]$ & нет & $5 T$ & V & мягкий & $\begin{array}{c}\text { варьирующие } \\
\text { клинические } \\
\text { проявления }\end{array}$ & \\
\hline 103 & c. $1364 C>A$ & p.Ala455Glu & A455E & V & мягкий & патогенный & \\
\hline 104 & c.1382G>A\# & p.Gly461Glu & G461E & III & неизвестно & не описан & \\
\hline 105 & c.1393-1G>A & нет & $1525-1 \mathrm{G}->A$ & 1 & тяжелый & патогенный & \\
\hline 106 & c. $1438 \mathrm{G}>\mathrm{A}$ & p.Gly480Ser & G480S & неизвестно & неизвестно & не описан & \\
\hline 107 & c. $1478 A>G$ & p.Gln493Arg & Q493R & неизвестно & неизвестно & не описан & \\
\hline 108 & $c .1487 G>A$ & p.Trp496X & W496X & $\mathrm{I}$ & тяжелый & патогенный & \\
\hline 109 & c. $1517 T>C$ & p.lle506Thr & $1506 \mathrm{~T}$ & $\|$ & тяжелый\# & не описан & \\
\hline 110 & c. $164+1 G>T$ & нет & $296+1 G->T$ & I & тяжелый & патогенный & \\
\hline 111 & c. $1646 G>A$ & p.Ser549Asn & S549N & III & тяжелый & патогенный & \\
\hline 112 & c.1680-1G>C\# & нет & & 1 & тяжелый & не описан & \\
\hline
\end{tabular}




\begin{tabular}{|c|c|c|c|c|c|c|}
\hline 113 & c.1704G>T & p.Leu568Phe & L568F & неизвестно & тяжелый & не описан \\
\hline 114 & c. $1705 T>G$ & p.Tyr569Asp & Y569D & III & неизвестно & патогенный \\
\hline 115 & c.1714G>A & p.Asp572Asn & D572N & неизвестно & тяжелый & не описан \\
\hline 116 & c. $1792 A>T$ & p.Lys598X & K598X & 1 & тяжелый & не описан \\
\hline 117 & c.1795_1796insAAA\# & p.Lys598dup & K598ins & неизвестно & неизвестно & не описан \\
\hline 118 & c.1811C>T & p.Thr604lle & $\overline{\left.T 604\right|^{*}}$ & неизвестно & тяжелый & не описан \\
\hline 119 & c.1986_1989delAACT & p.Thr663ArgfsX8 & 2118del4 & 1 & тяжелый & патогенный \\
\hline 120 & c.2053_2054insC & p.Gln685ProfsX84 & 2185insC & 1 & тяжелый & патогенный \\
\hline 121 & $c .2125 \mathrm{C}>\mathrm{T}$ & p.Arg709X & R709X & $\mathrm{I}$ & тяжелый & патогенный \\
\hline 122 & $c .2491 \mathrm{G}>\mathrm{T}$ & p.Glu831X & E831X & неизвестно & тяжелый & патогенный \\
\hline 123 & $c .2551 \mathrm{C}>\mathrm{T}$ & p.Arg851X & R851X & $\mathrm{I}$ & тяжелый & патогенный \\
\hline 124 & c. $2645 \mathrm{G}>\mathrm{A}$ & p.Trp882X & W882X & $\mathrm{I}$ & тяжелый & патогенный \\
\hline 125 & c. $2658-2 A>G$ & нет & $2790-2 A->G$ & 1 & тяжелый & не описан \\
\hline 126 & c. $274-1 \mathrm{G}>\mathrm{A}$ & нет & 406-1G->A & 1 & тяжелый & патогенный \\
\hline 127 & $c .274 G>T$ & p.Glu92X & E92X & $\mathrm{I}$ & тяжелый & патогенный \\
\hline 128 & c. $275 \mathrm{~A}>\mathrm{C} \#$ & p.Glu92Ala & & неизвестно & тяжелый & патогенный \\
\hline 129 & c. $2909 \mathrm{G}>\mathrm{A}$ & p.Gly970Asp & G970D & неизвестно & неизвестно & патогенный \\
\hline 130 & c. $3095 \mathrm{~A}>\mathrm{G}$ & p.Tyr1032Cys & Y1032C & неизвестно & мягкий & $\begin{array}{c}\text { варьирующие } \\
\text { клинические } \\
\text { проявления }\end{array}$ \\
\hline 131 & c. $3140-11 A>G$ & нет & $3272-11 A->G$ & V & мягкий & не описан \\
\hline 132 & c. $3197 G>A$ & p.Arg1066His & $\mathrm{R} 1066 \mathrm{H}$ & неизвестно & неизвестно & патогенный \\
\hline 133 & c. $3208 C>T$ & p.Arg1070Trp & R1070W & IV & неизвестно & $\begin{array}{c}\text { варьирующие } \\
\text { клинические } \\
\text { проявления }\end{array}$ \\
\hline 134 & c.3229_3230delCT & p.Leu1077ValfsX78 & 3359delCT & I & тяжелый & не описан \\
\hline 135 & c.3304A>T & p.Arg1102X & R1102X & 1 & тяжелый & патогенный \\
\hline 136 & $c .3310 \mathrm{G}>\mathrm{T}$ & p.Glu1104X & E1104X & I & тяжелый & патогенный \\
\hline 137 & c.3659delC & p.Thr1220LysfsX8 & 3791delC & 1 & тяжелый & патогенный \\
\hline 138 & $c .3746 \mathrm{G}>\mathrm{A}$ & p.Gly1249Glu & G1249E & неизвестно & неизвестно & не описан \\
\hline 139 & c.3763T>C & p.Ser1255Pro & S1255P & III & тяжелый & патогенный \\
\hline 140 & c. $3873+1 G>T$ & нет & $4005+1 G>T$ & 1 & тяжелый & не описан \\
\hline 141 & c.3893delG\# & p.Gly1298GlufsX30 & & I & тяжелый & не описан \\
\hline 142 & c. $3963+1 G>T$ & нет & $4095+1 G->T$ & 1 & тяжелый & не описан \\
\hline 143 & c.3983T>A\# & p.lle1328Lys & & неизвестно & неизвестно & не описан \\
\hline 144 & c.409_412delCTCC & p.Leu137TyrfsX15 & 541del4 & $\mathrm{I}$ & тяжелый & не описан \\
\hline 145 & $c .4234 \mathrm{C}>\mathrm{T}$ & p.Gln1412X & Q1412X & неизвестно & тяжелый & патогенный \\
\hline 146 & c. $4242+1 G>A$ & нет & $4374+1 G->A$ & I & тяжелый & патогенный \\
\hline 147 & c.4426C>T & p.GIn1476X & Q1476X & $\mathrm{VI}$ & мягкий & не описан \\
\hline 148 & c.494delT & p.Leu165X & 624delT & 1 & тяжелый & не описан \\
\hline 149 & c.531delT & p.lle177MetfsX12 & 663delT & I & тяжелый & патогенный \\
\hline 150 & $c .532 \mathrm{G}>\mathrm{A}$ & p.Gly178Arg & G178R & III & тяжелый & патогенный \\
\hline 151 & c.55T>G\# & p.Trp19Gly & W19G & неизвестно & мягкий & не описан \\
\hline 152 & $c .613 C>T$ & p.Pro205Ser & P205S & неизвестно & мягкий & патогенный \\
\hline 153 & $c .79 \mathrm{G}>\mathrm{T}$ & p.Gly27X & G27X & 1 & тяжелый & патогенный \\
\hline 154 & $c .868 \mathrm{C}>\mathrm{T}$ & p.GIn290X & Q290X & 1 & тяжелый & не описан \\
\hline 155 & c.948delT & p.Phe316LeufsX12 & 1078delT & 1 & тяжелый & патогенный \\
\hline 156 & c.264_268delATATT & p.Leu88PhefsX21 & & $\mathrm{I}$ & тяжелый & не описан \\
\hline 157 & c.3874-2A>G\# & нет & & I & тяжелый & не описан \\
\hline 158 & $\begin{array}{l}\text { c.(1679-1_1680+1)_(2490+1_2491-1) } \\
\text { del((2908+1_2989-1)del] \# }\end{array}$ & нет & $\begin{array}{l}\text { CFTRdele12,13; } \\
\text { del16^ }\end{array}$ & 1 & тяжелый & патогенный \\
\hline 159 & c. $2417 A>G$ & p.Asp806Gly & D806G & неизвестно & неизвестно & не описан \\
\hline 160 & c.1210-34T>G\# & нет & & неизвестно & мягкий & не описан \\
\hline 161 & c.1513A>C\# & p.Asn505His & & неизвестно & неизвестно & не описан \\
\hline 162 & c.2435T>A\# & p.Leu812X & & I & тяжелый & не описан \\
\hline 163 & c. $3112 C>T \#$ & p.GIn1038X & & I & тяжелый & не описан \\
\hline 164 & c.3232T $>A$ & p.Phe1078lle & & неизвестно & неизвестно & не описан \\
\hline 165 & c.451delC\# & p.GIn151ArgfsX2 & & I & тяжелый & не описан \\
\hline 166 & c.71_72delinsA\# & p.Leu24X & & 1 & тяжелый & не описан \\
\hline 167 & c.(2908+1_2909-1)_(3367+1_3368+1)del\# & нет & CFTRdele16-178^ & $\mathrm{I}$ & тяжелый & патогенный \\
\hline 168 & c.(2988+1_2989-1)_(3717+1_3718+1)del\# & нет & CFTRdele17a-19^ & I & тяжелый & патогенный \\
\hline 169 & c. $3189 \mathrm{G}>\mathrm{A}$ & p.Trp1063X & W1063X & 1 & тяжелый & не описан \\
\hline 170 & c.1708_1712delTTATT\# & p.Leu570ArgfsX17 & & $\mathrm{I}$ & тяжелый & не описан \\
\hline 171 & c.353delC\# & p.Ser118LeufsX6 & & I & тяжелый & не описан \\
\hline
\end{tabular}




\begin{tabular}{|c|c|c|c|c|c|c|}
\hline 172 & c.3927_3938delGTGGAGTGATCA\# & p.Trp1310_Gln1313del & & I & тяжелый & не описан \\
\hline 173 & c. $4404 A>C$ & p.Lys1468Asn & & неизвестно & мягкий & не описан \\
\hline 174 & c. $2619+1 \mathrm{G}>\mathrm{A} \#$ & нет & & $\mathrm{I}$ & тяжелый & не описан \\
\hline 175 & c.3908delA & p.Asn1303ThrfsX25 & 4040delA & I & тяжелый & патогенный \\
\hline 176 & c.613C>A\# & p.Pro205Thr & & неизвестно & мягкий & не описан \\
\hline 177 & c.1175T>G & p.Val392Gly & V392G & неизвестно & мягкий & не описан \\
\hline 178 & c.1528delG & p.Val510PhefsX17 & 1660delG & I & тяжелый & не описан \\
\hline 179 & c.1526G>T\# & p.Gly509Val & & неизвестно & неизвестно & не описан \\
\hline 180 & c.1608delA\# & p.Asp537ThrfsX3 & & неизвестно & тяжелый & не описан \\
\hline 181 & c.653T>A & p.Leu218X & L218X & I & тяжелый & не описан \\
\hline 182 & $c .697 \mathrm{C}>\mathrm{T}$ & p.Leu233Phe & L233F & неизвестно & неизвестно & не описан \\
\hline 183 & c. $1679+1634 A>G$ & нет & $1811+1,6 \mathrm{kbA}->\mathrm{G}$ & V & мягкий & не описан \\
\hline 184 & c.1580dupA\# & p.Glu528ArgfsX40 & & I & тяжелый & не описан \\
\hline 185 & c.1742T>G\# & p.Leu581X & & I & тяжелый & не описан \\
\hline 186 & c.458G>T\# & p.Arg153lle & & неизвестно & неизвестно & не описан \\
\hline 187 & c. $743+2 T>A \#$ & нет & c. $743+2 T>A$ & неизвестно & тяжелый & не описан \\
\hline 188 & c.(868+1_870-1)_(1116+1_1117-1)del\# & нет & ${\text { CFTRdele }{ }^{\wedge}}^{\wedge}$ & I & тяжелый & патогенный \\
\hline 189 & c. $2963 C>G$ & p.Pro988Arg & & неизвестно & мягкий & не описан \\
\hline 190 & $\begin{array}{c}\text { c. }\left(273-1 \_274+1\right)(869+1 \text { _870-1)del(1209- } \\
\text { 1_1210+1)_(1392+1_1393+1)del\# }\end{array}$ & нет & CFTRdel4-7; del9-10^ & I & тяжелый & патогенный \\
\hline 191 & c. $4298 \mathrm{~A}>\mathrm{G} \#$ & p.Glu1433Gly & & неизвестно & Мягкий & не описан \\
\hline 192 & c.2493delG\# & p.Glu831AspfsX13 & & I & тяжелый & не описан \\
\hline 193 & c. $1679+2 T>C$ & нет & & I & тяжелый & не описан \\
\hline 194 & c.3857T>C & p.Phe1205Ser & F1286S & неизвестно & мягкий & не описан \\
\hline 195 & c.(53+1_54-1)_(1116+1_1117-1)del\# & нет & CFTRdele2-7^ $^{\wedge}$ & I & тяжелый & патогенный \\
\hline 196 & c. $-593 A>G$ & нет & $-461 A->G$ & неизвестно & неизвестно & не описан \\
\hline
\end{tabular}

Примечание: \# - генетические варианты гена CFTR, не зарегистрированные в базах CFTR1 [2] и/или CFTR2 [9]; ^ - нумерация экзонов согласно традиционной номенклатуре.

Note: \# - genetic variants of CFTR gene, not registered in CFTR1 [2] and / or CFTR2 bases [9]; ^ - exons numeration according to traditional nomenclature.

Таблица 2

\section{Распределение генетических вариантов гена CFTR по типу у больных муковисиидозом из РФ в сравнении с мировыми данными (CFTR1)}

Table 2

\section{Distribution of genetic variants of CFTR gene by type in patients from the Russian Federation with cystic fibrosis compared to world data (CFTR1)}

\begin{tabular}{|c|c|c|c|c|}
\hline Тип мутации & Количество, $\mathrm{n}$ (РФ) & доля, $\%$ & Количество, $\mathrm{n}$ (CFTR1) [2] & доля, \% (CFTR1) [2] \\
\hline Делеции/инсерции без сдвига рамки считывания & 4 & 2,04 & 42 & 2,58 \\
\hline Делеции/инсерции со сдвигом рамки считывания & 40 & 20,41 & 319 & 19,62 \\
\hline Миссенс & 63 & 32,14 & 798 & 49,08 \\
\hline Нарушение сплайсинга & 33 & 16,84 & 228 & 14,02 \\
\hline Нонсенс & 43 & 21,94 & 169 & 10,39 \\
\hline Обширные перестройки (CVS) & 12 & 6,12 & 53 & 3,26 \\
\hline Прометенная мутация & 1 & 0,51 & 17 & 1,04 \\
\hline Всего & 196 & & 1626 & \\
\hline
\end{tabular}

Доли одиннадцати генетических вариантов превышают 1 \% (табл.1): c.1521_1523delCTT (F508del) 52,8 \%, c.54-5940_273+10250del21kb (CFTRdele2,3) $6,2 \%$, c.274G $>$ A (E92K) - 3,0 \%, c.2012delT (2143delT) $2,1 \%, \quad$ c.3718-2477C $>\mathrm{T} \quad(3849+10 \mathrm{kbC}->\mathrm{T})-2,0 \%$, c.3846G $>$ A $(\mathrm{W} 1282 \mathrm{X}) \quad-1,9 \%, \quad$ c.2052_2053insA (2184insA) - 1,8 \%, c.1545_1546delTA (1677delTA) $1,8 \%, \quad$ c.3909C $>\mathrm{G}(\mathrm{N} 1303 \mathrm{~K})-1,5 \%, \quad$ c. $1624 \mathrm{G}>\mathrm{T}$ (G542X) - 1,3 \%, c.413_415dupTAC (L138ins) - 1,2 \%. Их суммарная доля составляет 75,6 \%. Т. е. доля остальных 185 патогенных вариантов не превышает $12 \%(11,7 \%)$ от всех идентифицированных мутантных аллелей. В РФ доля гомозигот по c.1521_1523delCTТ (F508del) составила 29,6 \%, гетерозигот - 46,4\%, генотипов без c.1521_1523delCTT (F508del) - 24,0 \%.

Анализ Регистров больных МB за 2012-2016 годы и 2017 г. показывает соответствие спектров и относительных долей частых генетических вариантов, выявляемых в разные годы (табл. 3), что говорит о том, что данный спектр достаточно хорошо отражает 
Таблица 3

Относительные частоты наиболее распространенных генетических вариантов гена CFTR у российских пациентов в разнье годь

Table 3

Relative frequencies of the most common genetic variants of CFTR gene in Russian patients in different years

\begin{tabular}{|c|c|c|c|c|c|c|c|c|}
\hline \multirow[t]{2}{*}{ № } & \multirow[t]{2}{*}{ Название по cDNA } & \multirow{2}{*}{$\begin{array}{l}\text { Традиционное } \\
\text { название }\end{array}$} & 2017 & $\begin{array}{l}2016 \\
{[10]} \\
\end{array}$ & $\begin{array}{l}2015 \\
{[11]} \\
\end{array}$ & $\begin{array}{l}2014 \\
{[12]} \\
\end{array}$ & $\begin{array}{l}2013 \\
{[13]}\end{array}$ & $\begin{array}{l}2012 \\
{[14]}\end{array}$ \\
\hline & & & $\%$ & $\%$ & $\%$ & $\%$ & $\%$ & $\%$ \\
\hline 1 & c.1521_1523delCTT & F508del & 52,8 & 52,06 & 51,67 & 51,53 & 52,21 & 52,85 \\
\hline 2 & c.54-5940_273+10250del21kb & CFTRdele2,3 & 6,2 & 5,71 & 5,68 & 5,93 & 5,94 & 5,91 \\
\hline 3 & c. $274 G>A^{*}$ & E92K & 3,0 & 2,67 & 2,43 & 2,62 & 2,58 & 2,64 \\
\hline 4 & c.2012delT & 2143delT & 2,1 & 2,06 & 1,90 & 1,69 & 1,67 & 1,72 \\
\hline 5 & c.3718-2477C>T & $3849+10 \mathrm{kbC}->\mathrm{T}$ & 2,0 & 2,04 & 2,10 & 2,14 & 2,18 & 2,10 \\
\hline 6 & c. $3846 \mathrm{G}>\mathrm{A}$ & W1282X* & 1,9 & 1,82 & 1,82 & 1,80 & 1,43 & 1,05 \\
\hline 7 & c.2052_2053insA & 2184insA & 1,8 & 1,87 & 1,80 & 1,80 & 1,69 & 1,76 \\
\hline 8 & c.1545_1546delTA & 1677delTA* & 1,8 & 1,44 & 1,29 & 0,98 & 0,77 & 0,50 \\
\hline 9 & c. $3909 \mathrm{C}>\mathrm{G}$ & N1303K & 1,5 & 1,47 & 1,35 & 1,43 & 1,46 & 1,43 \\
\hline 10 & c. $1624 G>T$ & G542X & 1,3 & 1,35 & 1,18 & 1,16 & 1,09 & 1,34 \\
\hline 11 & c.413_415dupTAC & L138ins & 1,2 & 1,15 & 1,07 & 0,95 & 1,00 & 1,09 \\
\hline 12 & c.262_263delTT & 394delTT & 0,9 & 0,89 & 0,82 & 0,85 & 0,89 & 0,97 \\
\hline 13 & c. $1000 \mathrm{C}>\mathrm{T}$ & R334W & 0,8 & 0,80 & 0,80 & 0,85 & 0,86 & 0,67 \\
\hline 14 & c. $3844 \mathrm{~T}>\mathrm{C}$ & W1282R* & 0,6 & 0,42 & 0,29 & 0,29 & 1,43 & 0,25 \\
\hline 15 & c. $1397 C>G$ & $S 466 X^{*}$ & 0,5 & 0,33 & 0,27 & 0,37 & 0,31 & 0,25 \\
\hline 16 & c. $2657+5 G>A$ & $2789+5 G>A^{*}$ & 0,5 & 0,33 & 0,33 & 0,37 & 0,34 & 0,25 \\
\hline 17 & c. $3587 \mathrm{C}>\mathrm{G}$ & S1196X & 0,5 & 0,40 & 0,33 & 0,37 & 0,40 & 0,50 \\
\hline 18 & c.3691delT & 3821delT* & 0,5 & 0,44 & 0,45 & 0,42 & 0,32 & 0,25 \\
\hline
\end{tabular}

Примечание: ${ }^{*}$ - варианты нуклеотидной последовательности гена CFTR, относительные доли которых увеличились за период тестирования.

Note: ${ }^{*}$ - variants of nucleotide sequence of CFTR gene, relative shares of which have increased during the testing period.

реальное распределение мутантных аллелей гена CFTR у российских пациентов с MB. Увеличение почти вдвое относительных частот ряда вариантов (в таблице 3 отмечены знаком «*») в 2017 г. по сравнению с данными 2012 г., вероятно, связано с тем, что в 2012 году не во всех лабораториях проводили тестирование этих вариантов, а также с тем, что эти варианты распространены в регионах и этнических группах, которые в 2012 году были недостаточно полно обследованы. Так, варинат с.3846G>A (W1282X) является преобладающим у карачаевцев (до 90 \% всех мутантных аллелей), вариант с.1545_1546delTA (1677delTA) у чеченцев (более $60 \%$ всех МВ аллелей).

58 из 196 вариантов нуклеотидной последовательности, выявленных у российских пациентов с МB в 2017г., впервые были идентифицированы у российских пациентов. Несколько из них зарегистрированы, внесены в базы CFTR1 и/или CFTR2, относятся к частым и включены в панели молекулярной диагностики MB на первом этапе: c.54-5940_273+10250del21kb (CFTRdele2,3), c.1545_1546delTA (1677delTA), c.3844T>C (W1282R), c.3691delT (3821delT), c.472dupA (604insA). Ряд других вариантов, внесенных в базу CFTR1, были обнаружены однократно (например,
c.264_268delATATT; c.4404A>C; c.494delT, c.1714G>A (D572N). 44 из выявленных генетических вариантов пока не приведены в базах CFTR1 и CFTR2 и требуют подтверждения клинической значимости с помощью тестов, характеризующих работу CFTR канала [15].

У российских пациентов выявлены 12 вариантов нуклеотидной последовательности, представляющих варьирование копийности участков гена CFTR - 8 делеций и 2 дупликации, затрагивающие несколько экзонов и интронов (табл. 1 и 2). Три предсталены в базе CFTR1 [2] и/или CFTR2 (с.54-5940_273+10250del21kb (CFTRdele2,3); c. (743+1_744-1)_(1584+1_1585-1) dup (CFTRdup6b-10); c.(53+1_54-1)_(164+1_165-1) del (CFTRdele2)). Остальные выявлены впервые. Четыре варианта обнаружены неоднократно: вариант c.54-5940_273+10250del21kb (CFTRdele2,3) является вторым по частоте у российских пациентов; вариант c.(743+1_744-1)_(1584+1_1585-1)dup (CFTRdup6b-10) встретился у 5 неродственных пациентов; варианты c.(743+1_744-1)_(1116+1_1117-1)dup (CFTRdup6b,7) и с.(273+1_274-1)_(1679+1_1680-1)del (CFTRdele4-10) - каждый у двух больных. Суммарная доля обширных перестроек составила 6,54 \% от всех идентифицированных мутантных аллелей гена CFTR. 
Это значительно выше, чем во многих популяциях мира, где доля геномных перестроек гена CFTR не превышает 1-2 \% [16].

Полученные результаты дают общее и несколько смещенное представление о разнообразии и частоте патогенных вариантов гена CFTR у российских пациентов с MB, что может быть связано с рядом особенностей проведения тестирования:

- настоящее исследование включает результаты ДНК-тестирования пациентов, включенных в Регистр только 2017 г., т.е. ряд генетических вариантов мог быть не учтен в текущем году, если их носители не были включены в Регистр. В основном это касается редких вариантов;

- ДНК-тестирование не является обязательным этапом при диагностике МВ, в том числе и в ходе неонатального скрининга в России. Поэтому во многих регионах обследованы не все больные с установленным диагнозом (хотя и внесенные в Регистр больных МB);

- для большей части пациентов выполнен только первый этап ДНК-тестирования, включающий анализ ограниченного спектра генетических вариантов (от 11-16 до 35);

- в ряде случаев у пациентов с МВ не удается обнаружить двух патогенных вариантов, даже при выполнении расширенного анализа, включающего секвенирование кодирующей области и поиска обширных перестроек гена CFTR. Это может быть связано с расположением ранее неизвестных патогенных вариантов либо во внутренних регионах интронов, либо в регуляторных областях гена CFTR, либо в регуляторных регионах вне гена CFTR, атипичных случаев MB или MB-подобных состояний, связанных с нарушением работы иных генов.

Проблема разнообразия и распределения патогенных генетических вариантов гена CFTR по типам в различных популяциях продолжает обсуждаться, особенно в связи с разработкой и внедрением таргетной терапии муковисцидоза в практическое здравоохранение [17, 18, 19].

Среди выявленных мутаций, по данным Регистра больных муковисцидозом РФ в 2017 году, следует отметить значительное разнообразие генетических вариантов I класса (табл. 1). По состоянию на сегодняшний день таргетная терапия для мутаций I класса не разработана, но исследования в данном направлении продолжаются [20].

В перспективе, возможно, рекомендовать использовать достижения таргетной терапии при лечении пациентов, носителей следующих генотипов,: гомозигот по с.1521_1523delCTT (F508del) (571 пациентов старше 6 лет в РФ) и гетерозиготных компаундов по c.1521_1523delCTT (F508del) и вариантам c.1364C >A (A455E) (1 пациент в РФ), с.2834C>T (S945L) (5 пациентов в РФ), с.3208C $>\mathrm{T}(\mathrm{R} 1070 \mathrm{~W})$ (1 пациент в РФ), c.3454G $>$ C D1152H (5 пациентов в PФ), с.350G >A
(R117H) (2 пациента в PФ), с.349C>T (R117C) (5 пациентов в PФ), G551D (2 пациента в PФ), с.1646G >A (S549N) (1 пациент в PФ), с.3763T >C (S1255P) (1 пациент в РФ), с.2491G>T (E831X) (1 пациент в РФ), c.532G >A (G178R) (1 пациент в РФ), с.3718-2477C>T $(3849+10 \mathrm{kbC}->\mathrm{T})(110$ пациентов в РФ), с.3140-26A $>\mathrm{G}$ (3272-26A->G) (2 пациента в $Р \Phi), \quad$ с.2657+5G $>A$ $(2789+5 \mathrm{G}>\mathrm{A})(27$ пациентов в РФ) [21, 22, 23].

\section{Заключение}

На основании данных Регистра 2017 года представлены спектры и относительные частоты частых и редких патогенных вариантов последовательности гена CFTR у российских больных MB; описано распределение выявленных генетических вариантов в зависимости от класса и типа. Выявлены генетические варианты, ранее не описанные в базах CFTR1 и CFTR2. Описание клинического течения MB у пациентов, носителей данных вариантов необходимо для пополнения баз CFTR1 и CFTR2. Полученные результаты могут использоваться для оптимизации генетического консультирования и клинической работы с семьями, отягощенными $\mathrm{MB}$, а также для дальнейших исследований патогенетической значимости ранее не описанных генетических вариантов гена CFTR.

\section{Литература/References}

1. Strausbaugh SD, Davis PB. Cystic fibrosis: a review of epidemiology and pathobiology. Clinical Chest Medicine. 2007;(28):279-88. DOI: 1016/j.ccm.2007.02.011

2. The Cystic Fibrosis Mutation Database. Accessed December 25, 2018. http://www.genet.sickkids.on.ca

3. EXAC The Exome Aggregation Consortium (Exac) Database. Accessed December 25, 2018. http://exac.broadinstitute.org/gene/ENSG00000001626

4. De Boeck K, Vermeulen F, Dupont L. The diagnosis of cystic fibrosis. Presse Medicale. 2017;46(6 Pt 2):e97-e108. DOI: 1016/j.lpm.2017.04.010

5. Marson FA, Bertuzzo CS, Ribeiro JD. Classification of CFTR mutation classes. The Lancet. Respiratory Medicine. 2016; 4 (8):37-8. DOI:1016/S2213-2600(16)30188-6

6. Петрова НВ, Кондратьева ЕИ, Красовский СА, Поляков АВ, Иващенко ТЭ, Павлов АЕ, Зинченко РА, Гинтер ЕК, Куцев СИ, Одинокова ОН, Назаренко ЛП, Капранов НИ, Шерман ВД, Амелина ЕЛ, Ашерова ИК, Гембицкая ТЕ, Ильенкова НА, Каримова ИП, Мерзлова НБ, Намазова-Баранова ЛС, Неретина АФ, Никонова ВС, Орлов АВ, Протасова ТА, Семыкин СЮ, Сергиенко ДФ, Симонова О.И, Шабалова ЛА, Каширская НЮ. Проект национального консенсуса «Муковисцидоз: определение, диагностические критерии, терапия» Раздел «Генетика муковисцидоза. Молекулярно-генетическая диагностика при муковисцидозе». Медицинская генетика. 2016;11(173):29-45. [Petrova NV, Kondratyeva EI, Krasovsky SA, Polyakov AV, Ivachshenko TE, Pav lov AE, Zinchenko RA, Ginter EK, Kutsev SI, Odinokova ON, Nazarenko LP, Kapranov NI, Sherman VD, Amelina EL, Asherova IK, Gembitskaya TE, Ilyenkova NA, Karimova IP, Merzlova NB, 
Namazova-Baranova LS, Neretina ÀF, Nikonova VS, Orlov AV, Protasova TA, Semykin SY, Sergienko DF, Simonova OI, Shabalova LA, Kashirskaya NY. National Consensus Project "Cystic fibrosis: definition, diagnostic criteria, treatment» Section «Genetics of Cystic Fibrosis. Molecular genetic diagnosis of cystic fibrosis». Medical Genetics. 2016;11(173):P2945. (In Russian)]

7. Richards S, Aziz N, Bale S, Bick D, Das S, Gastier-Foster J, Grody WW, Hegde M, Lyon E, Spector E, Voelkerding K, Rehm HL, ACMG. Laboratory Quality Assurance Committee Standards and guidelines for the interpretation of sequence variants: a joint consensus recommendation of the American. College of Medical Genetics and Genomics and the Association for Molecular Pathology. Genetics in Medicine. 2015;17(5):405-424. DOI:1038/gim.2015.30

8. Рыжкова ОП, Кардымон ОЛ, Прохорчук ЕБ, Коновалов ФА, Масленников АБ, Степанов ВА, Афанасьев АА, Закллязьминская ЕВ, Костарева АА, Павлов АБ, Голуббенок МВ, Поляков АВ, Куцев СИ. Руководство по интерпретации данных, полученных методом массового параллельного секвенирования (MPS). Медицинская генетика. 2017;(7):4-17. [Ryzhkova OP, Kardimon OL, Prohorchuk EB, Konovalov FA, Maslennikov AB, Stepanov VA, Afanasyev AA, Zaklyazminskaya EV, Kostareva AA, PavlovAE, Golubenko MV, Polyakov AV, Kutsev SI. Guidelines for the interpretation of massive sequencing variants. Medical Genetics. 2017;(7):4-17. (In Russian)]

9. Clinical and Functional Translation of CFTR (CFTR2). Accessed December 25, 2018. https://www.cftr2. org/mutations_history

10. Регистр больных муковисцидозом в Российской Федерации. 2016 год / Под редакцией Красовского СА, Черняка АВ, Воронковой АЮ, Амелиной ЕЛ, Каширской НЮ, Кондратьевой ЕИ, Гембицкой ТЕ. М.: МЕДПРАКТИКА-М; 2018. 64 с. [Register of patients with cystic fibrosis in the Russian Federation. 2016. Edited by Krasovsky S A, Chernyak AV, Voronkova AYu, Amelina EA, Kashirskaya NYu, Kondratieva EI, Gembitskaya TE. Moscow: MEDPRAKTIKA-M; 2018. 64 p. (In Russian)]

11. Регистр больных муковисцидозом в Российской Федерации. 2015 год / Под редакцией Кондратьевой ЕИ, Красовского СА, Воронковой АЮ, Амелиной ЕЛ, Черняка АВ, Каширской НЮ. М. : МЕДПРАКТИKA-M; 2016. 72 c. [Register of patients with cystic fibrosis in the Russian Federation. 2015. Edited By Kondrateva EI, Krasovsky SA, Voronkova AYu, Amelina EL, Chernyak AV, Kashirskaya NYu. Moscow: MEDPRAKTIKA-M; 2016. 72 p. (In Russian)]

12. Регистр больных муковисцидозом в Российской Федерации. 2014 год. М. : МЕДПРАКТИКА- М; 2015. 64 c. [Register of patients with cystic fibrosis in the Russian Federation. 2014. Moscow: MEDPRAKTIKA - M; 2015. 64 p. (In Russian)]

13. Регистр больных муковисцидозом в Российской Федерации. 2013 год. М.: МЕДПРАКТИКА-М; 2015. 64 c. [Register of patients with cystic fibrosis in the Russian Federation. 2013. Moscow: MEDPRAKTIKA-M; 2015. 64 p. (In Russian)]
14. Регистр больных муковисцидозом в Российской Федерации. 2012 год. Ссылка активна на 25.12.2018. [Register of patients with cystic fibrosis in the Russian Federation. 2012. Assessed December 25, 2018. (In Russian)] http://mukoviscidoz.org/doc/registr/ Registr_2012_27.02.pdf

15. Кондратьева ЕИ, Мельяновская ЮЛ, Шерман ВД, де Йонге ХР, Ефремова АС, Бухарова ТБ, Гольдштейн ДВ, Зодьбинова АЭ. Функциональные методы диагностики нарушений гена CFTR и его продукта (Обзор литературы). Вопросы Практической Педиатрии. 2018;13(4):5064. [Kondratieva EI, MeljanovskayaYuL, Sherman VD, de Yonge XP, Efremova AS, Bukharova TB, Goldstein DV, Zodbinova AE. Functional methods for the diagnosis of disorders of the CFTR gene and its product (Review). Voprosy Practicheskoy Pediatriy (Questions of Practical Pediatrics). 2018;13(4):50-64. (In Russian)]

16. Castellani C, Cuppens H, Macek MJr, Cassiman JJ, Kerem E, Durie P, Tullis E, Assael BM, Bombieri C, Brown A, Casals T, Claustres M, Cutting GR, Dequeker E, Dodge J, Doull I, Farrell P, Ferec C, Girodon E, Johannesson M, Kerem B, nowles M, Munck A, Pignatti PF, Radojkovic D, Rizzotti P, Schwarz M, Stuhrmann M, Tzetis M, Zielenski J, Elborn JS. Consensus on the use and interpretation of cystic fibrosis mutation analysis in clinical practice. Journal of Cystic Fibrosis. 2008;7(3):179-196. DOI: 10.1016/j.jcf.2008.03.009

17. FDA approves Kalydeco to treat rare form of cystic fibrosis (Press release). Food and Drug Administration, 31 January 2011. Assessed December 25, 2018. https://www. prnewswire.com/news-releases/fda-approves-kalydeco-totreat-rare-form-of-cystic-fibrosis-138405949.html

18. Vertex Wins Approval for Kalydeco to Treat Cystic Fibrosis. Bloomberg Businessweek. Retrieved 24 June 2012. Assessed December 25, 2018. https://www.bloomberg.com/ businessweek/news/2012-01-31/vertex-wins-approval-forkalydeco-to-treat-cystic-fibrosis.html

19. Cohen D, Raftery J. Paying twice: questions over high cost of cystic fibrosis drug developed with charitable funding. BMJ. 2014; (348): g1445. DOI:10.1136/bmj.g1445

20. Study of Ataluren (PTC124) in Cystic Fibrosis Assessed December. 25, 2018. https://clinicaltrials.gov/ct2/ show/NCT02107859

21. Van Goor F, Hadida S, Grootenhuis PD, Burton B, Stack JH, Straley KS, Decker CJ, Miller M, McCartney J, Olson ER, Wine JJ, Frizzell RA, Ashlock M, Negulescu PA. Correction of the F508del-CFTR protein processing defect in vitro by the investigational drug VX-809. Proceedings of the National Academy of Sciences of the United States of America. 2011;108(46):18843-18848. DOI: 10.1073/pnas. 1105787108

22. Study of VX-809 alone and in combination with VX770 in cystic fibrosis (CF) patients homozygous or heterozygous for the F508del-CFTR mutation. Assessed December. 25, 2018. http://clinicaltrials.gov/ct2/show/NCT01225211?ter$\mathrm{m}=\mathrm{ivacaftor} \& \mathrm{int}=\mathrm{ivacaftor} \& \mathrm{ra} \mathrm{nk}=4$.

23. Van GF, Burton B, Hoffman BJ. Effect of ivacaftor on CFTR forms with missense mutations associated with defects in protein processing or function. Journal of Cystic Fibrosis. 2014; 3:29-36. DOI: 10.1016/j.jcf.2013.06.008 


\section{Сведения об авторах}

Петрова Ника Валентиновна, д.б.н., Медико-генетический научный иентр; адрес: Российская Федеращия, 115522, г. Москва, ул. Москворечье, дом 1; тел.: +7(499)3206090; e-mail: npetrova63@mail.ru

Кондратьева Елена Ивановна, д.м.н., профессор, Медико-генетический научный центр адрес: Российская Федеращия, 115522, г. Москва, ул. Москворечье, дом 1; тел.: +7(495)5873366, 7(916)2553385; e-mail: elenafpk@mail.ru

Поляков Александр Владимирович, д.б.н., профессор, Медико-генетический научный иентр; адрес: Российская Федерация, 115522, г. Москва, ул. Москворечье, дом 1; тел.: +7(499)6129846; e-mail: polyakov@med-gen.ru

Иващенко Татьяна Эдуардовна, д.б.н., профессор, Научно-исстедовательский институт акушерства, гинекологии и репродуктологии им. Д. О. Отта; адрес: Российская Федеращия, 199034, г. Санкт-Петербург, Менделеевская линия, д. 3; тел.: +7(812)3289809; e-mail: tivashchenko2011@mail.ru

Павлов Александр Евгеньевич, $О 00$ «Парсек Лаб»; адрес: Российская Федера ичя, 197350, г. Санкт-Петербург, дорога в Каменку, дом 74А, помещение 1, комн 347 meл.: +7(812)2431190; e-mail: apavlov@sequoiag.com

Зинченко Рена Абульфазовна, д.м.н., профессор, Медико-генетический научный иентр адрес: Российская Федерация, 115522, г. Москва, ул. Москворечье, дом 1; профессор курса кли нической фармакологии кафедры организационно-правого обеспечения медицинской и фармаиевтической деятельности, Московский областной научно-исследовательский клиниче

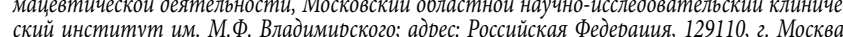
ул. Щепкина 61/2, корпус 1; тел.: +7(499)3241224; e-mail: renazinchenko@mail.ru

Гинтер Евгений Константинович, д.б.н., профессор, академик РАН, Медико-генетиче ский научньй иентр; адрес: Российская Федерация, 115522, г. Москва, ул. Москворечье, дом 1; тел.: +7(499)6120037; e-mail: mgnc@med-gen.ru

Одинокова Ольга Николаевна, к.м.н., Томский национальный исследовательский медицинский центр; адрес: Российская Федерация, 634009, г. Томск, Московский тракт, 3 meл.: +7(382)2515681; e-mail: olga.odinokova@medgenetics.ru

Назаренко Людмила Павловна, д.м.н., профессор, Томский начиональный исследовательский медиинский центр; адрес: Российская Федеращия, 634009, г. Томск, Московскии тракт, 3; тел.: +7(3822)535683; e-mail: ludmila.nazarenko@medgenetics.ru

Капранов Николай Иванович, д.м.н., профессор, Медико-генетический научный иентр адрес: Россиисккая Федерация, 115522, г. Москва, ул. Москворечье, дом 1; тел.: +7(495)5873366; e-mail: 84955873366@mail.ru

Амелина Елена Львовна, к.м.н., Научно-исстедовательский институт пудьмонологии; адрес: Российская Федераиия, 105077, г. Москва, ул. 11-я Парковая, 32, корп. mел.: +7(499)7800806; e-mail: eamelina@mail.ru

Старинова Марина Александровна, Медико-генетический научный иентр; адрес: Российская Федеращия, 115522, г. Москва, ул. Москворечье, дом 1; тел.: +7(495)5873366; e-mail: registrycfrf@gmail.com

Куцев Сергей Иванович, д.м.н., профессор, член-корреспондент РАН, Медико-генетиче ский научный центр; адрес: Российская Федераиия, 115522, г. Москва, ул. Москворечье, дом 1; mел.: +7(499)6120037; e-mail: mgnc@med-gen.ru

Ижевская Вера Леонидовна, д.м.н., Медико-генетический научный иентр; адрес: Российская Федерачия, 115522, г. Москва, ул. Москворечье, дом 1; тел.: +7(499)3241534 e-mail: izherskaya@med-gen.ru

Кондратенко Ольга Владимировна, д.м.н., Клиники Самарского государственного медищинского университета, адрес: Российская Федеращия, 443079, г. Самара, ул. Карла Маркса пр., 1655; meл.: +7(846)2648305; e-mail: baclab-samara@yandex.ru

Бойченко Елена Александровна, Самарская областная детская клиническая больнии им. Н.Н. Ивановой; адрес: Российская Федеращия, 443079, г. Самара, ул. Карла Маркса пр., 165A; тел.: +7(846)2500755; e-mail: mail@1dgkb.ru

Козлов Андрей Владимирович, Клиники Самарского государственного медииинского университета, адрес: Российская Федеращия, 443079, г. Самара, ул. Карла Маркса пр., 165Б тел.: +7(846)2648305; e-mail: baclab-samara@yandex.ru

Бойиова Евгения Викторовна, д.м.н., профессор, Санкт-Петербургский государственный педиатрический медииинский университет; адрес: Российская Федерация, 194100, Санкт-Петербург, ул. Литовская, д. 2; тел.: +7(812)2950871; e-mail: Aleks-Shabalov2007@ yandex.ru.

Гембиикая Татьяна Евгеньевна, д.м.н., профессор, Первый Санкт-Петербургский государственный медииинский университет им. акад. И.П. Павлова; адрес: Российская Федераиия, 197022, г. Санкт-Петербург, ул. Льва Толстого, д. 6-8; тел.: +7(812)3386625; e-mail: mukoviscidoz_otd@mail.ru

Москвина Дарья Михайловна, Первый Санкт-Петербургский государственный ме дицинский университет им. акад. И.П. Павлова; адрес: Российская Федерация, 197022, 2. Санкт-Петербург, ул. Рентгена, д. 12; тел.: +7(812)5425362; e-mail: mosquina.daria@yandex. ru

Степаненко Татьяна Александровна, к.м.н., Городская многопрофильная больница №2 адрес: Российская Федераиия, 194354, Учебный пер., д. 5; тел.: +7(812)3389486; е-таil: b2@ zdrav.spb.ru

Филиппова Татьяна Андреевна, Городская многопрофильная больнииа №2; адрес: Российская Федераиия, 194354, Учебный пер., д. 5; тел.: +7(812)3389331; е-mail: b2@zdrav.spb.ru Коновалова Людмила Евгеньевна, Детская клиническая больница; адрес: Российская Федеращия, 195009, г. Санкт-Петербург, ул. Комсомола, д. 6; тел.: +7(812)5420191; e-mail: dkb@lodkb.ru

Махмутова Виктория Ринатовна, Городская многопрофильная больница №2; адрес Российская Федераиия, 194354, Учебный пер., д. 5; тел.: +7(812)3389331; e-mail: b2@zdrav.spb.ru Орлов Александр Владимирович, Детская городская больнииа Святой Ольги адрес: Российская Федераиия, 194156, г. Санкт-Петербург, ул. Земледельческая, д. 2, meл.: +7(812)2956998; e-mail: pulmonology3@hotmail.com

Пашкевич Александр Анатольевич, Детская городская больница Святой Ольги; адрес: Российская Федеращия, 194156, г. Санкт-Петербург, ул. Земледельческая, д. 2 meл.: +7(812)2956992; e-mail: pulmonology3@hotmail.com

Никитина Марина Ивановна, Детская городская больница Святой Ольги, адрес: Российская Федераиия, 194156, г. Санкт-Петербург, ул. Земледельческая, д. 2, тел.: +7(812)2956992; e-mail: pulmonology3@hotmail.com

Ковалев Виктор Николаевич, Детская городская больница Святой Ольги адрес: Российская Федераиия, 194156, г. Санкт-Петербүрг, ул. Земледельческая, д. meл.: +7(812)2956992; e-mail: pulmonology3@hotmail.com

Игнатьева Мария Николаевна, Детская городская больниия Святой Ольги адрес: Российская Федерация, 194156, г. Санкт-Петербург, ул. Земледельческая, д. 2; meл.: +7(812)2956992; e-mail: pulmonology3@hotmail.com

ушатская Оксана Александровна, Детская городская больнииа Святой Ольги; адрес: Российская Федерация, 194156, г. Санкт-Петербург, ул. Земледельческая, д. 2, тел.: +7(812)2956992; e-mail:pulmonology3@hotmail.com
Борисенко Тарас Сергеевич, Детская городская больнииа Святой Ольги; адрес: Российская Федерация, 194156, г. Санкт-Петербург, ул. Земледельческая, д. 2; тел.: +7(812)2956992 e-mail:pulmonology3@hotmail.com

Антипова Любовь Анатольевна, Детская городская больница Святой Ольги адрес: Российская Федерачия, 194156, г. Санкт-Петербург, ул. Земледельческая, д. 2, тел.: +7(812)2956992; e-mail: pulmonology3@hotmail.com

Пономарева Наталья Дмитриевна, Свердловская областная клиническая больни№1; адрес: Российская Федераиия, 620102, г. Екатеринбург, ул. Волгоградская, д. 185; meл.: +7(343)3511532; e-mail: office@okb1.ru

Шуляк Ирина Павловна, Областная детская клиническая больница №1; адрес: Российская Федеращия, 620149, г. Екатеринбург, ул. Серафимы Дерябиной, д. 32, тел.: +7(343)2405780; e-mail: odkb-public@mis66.ru

Новикова Ольга Борисьевна, к.м.н., Смоленский государственный медииинский университет; адрес: Российская Федерация, 214019, г. Смоленск, ул. проезд Маршала Конева, д. 30; тел.: +7(481)2555494; e-mail: gospedfpk@smolgmu.ru

Алимова Ирина Леонидовна, д.м.н., профессор, Смоленская областная детская клиническая больница; адрес: Российская Федеращия, 214019, ул. Маршала Конева, д. 30В; Смотенский государственный медииинский университет; адрес: Российская Федераиия, 214019 2. Смоленск, ул. Маршала Конева, д. 30; тел.: +7(481)2555494; e-mail: gospedfpk@smolgmu.ru

Водовозова Элла Владимировна, к.м.н., Ставропольский государственный медицинский университет; адрес: Российская Федерация, 355017, г. Ставрополь, ул. Мира, д. 310 тел.: +7(865)2352331; e-mail: postmaster@stgmu.ru

Леденева Лариса Николаевна, к.м.н., Ставропольский государственный медииинский университет; адрес: Российская Федерация, 355017, г. Ставрополь, ул. Мира, д. 310; тел.: +7(865)2352331; e-mail:postmaster@stgmu.ru

Енина Елена Александровна, к.м.н., Краевая детская клиническая больнииа; адрес: Российская Федераиия, 355029, г. Ставрополь, ул. Семашко, д. 3; тел.: +7(865)2357338; -mail: kdkb@skkdkb.ru

Пономарева Татьяна Александровна, Ставропольский государственный медицинский университет; адрес: Российская Федерация, 355017, г. Ставрополь, ул. Мира, д. 310 тел.: +7(865)2352331; e-mail: postmaster@stgmu.ru

Оганесян Инна Самвеловна, Краевая детская клиническая больнииа; адрес: Российская Федераиия, 355029, г. Ставрополь, ул. Семашко, д. 3; тел.: +7(865)2357338; e-mail: kdkb@ skkdkb.ru

Канукова Наталья Андреевна, Ставропольский краевой клинический консультативно-диагностический иентр; адрес: Российская Федерачия, 355017, г. Ставрополь, ул. Ленина, d. 304; meл.: +7(865)2951951; e-mail: skkdc@skkdc.ru

Алексанян Мери Эдиковна, Тамбовская областная детская клиническая больнииа адрес: Российская Федерация, 392000, г. Тамбов, ул. Рылеева, д. 80; тел.: +7(475)2580435 e-mail:post@odb.tambov.gov.ru

Закурнаева Елена Владимировна, Тамбовская областная детская клиническая больнииа; адрес: Российская Федеращия, 392000, г. Тамбов, ул. Рылеева, д. 80; тел.: +7(475)2580435; e-mail:post@odb.tambov.gov.ru

Филимонова Маргарита Николаевна, Томский наииональный исследовательский медииинский центр; адрес: Российская Федерация, 634009, г. Томск, Московский тракт, 3 mел.: +7(382)2533625; e-mail: margarita.flimonova@medgenetics.ru

Смирнова Ирина Ивановна, Томский национальный исстедовательский медицинский центр; адрес: Российская Федеращия, 634009, г. Томск, Московский тракт, 3; тел.: +7(382 2530537; e-mail: genetics@tnimc.ru

Мухачева Валерия Викторовна, Томский национальный исследовательский медииинскии иентр; адрес: Российская Федеращия, 634009, г. Томск, Московский тракт, 3; meл.: +7(3822)530537; e-mail:genetics@tnimc.ru

Калинина Юлия Эриховна, Тульская детская областная клиническая больнииа; адрес: Российская Федеращия, 300010, г. Тула, ул. Бондаренко, д. 39; тел.: +7(4872)480130; e-mail:guz.tdokb@tularegion.ru

Булатова Ирина Алексеевна, Областная клиническая больнииа №1; адрес: Российская Федеращия, 625023, г. Тюмень, ул. Котовского, д. 55/4; тел.: +7(345)2560010 e-mail:tmn560010@gmail.com

Трясиына Наталья Викторовна, Областная клиническая больнииа №1; адрес: Российская Федерация, 625023, г. Тюмень, ул. Котовского, д. 55/4; тел.: +7(345)2560010; e-mail:tmn560010@gmail.com

Симанова Татьяна Владимировна, Республиканская детская клиническая больнииа; адрес: Российская Федерачия, 426009, г. Ижевск, ул. Ленина, д. 79; тел.: +7(341)2330363; e-mail: rdkb-priem@mail.ru

Осипова Елена Валерьевна, к.м.н., Первая республиканская клиническая больница; адрес: Российская федерация, 426000, г. Ижевск, ул. Воткинское шоссе, д. 57 тел.: +7(341)2468771; e-mail: main@rkb1.udm.ru

Стародубиева Оксана Ивановна, Первая республиканская клиническая больнииа; адрес Российская Федерация, 426000, г. Ижевск, ул. Воткинское шоссе, д. 57; тел.: +7(341)2204700; e-mail:main@rkb1.udm.ru

Муралева Наталия Петровна, Республиканская детская клиническая больнища; адрес: Российская Федерачия, 426009, г. Ижевск, ул. Ленина, д. 79; тел.: +7(341)2330363; e-mail: rdkbpriem@mail.ru

Кочергина Татьяна Анатольевна, Первая республиканская клиническая больница; адрес: Российская Федерация, 426000, г. Ижевск, ул. Воткинское шоссе, д. 57; mел.: +7(341)2465483; e-mail: main@rkb1.udm.ru

Гоголева Елена Владимировна, Республиканская детская клиническая больнииа; адрес: Российская Федерация, 426009, г. Ижевск, ул. Ленина, д. 79; тел.: +7(341)2330363; e-mail: rdkbpriem@mail.ru

Губарева Татьяна Александровна, Ульяновская областная детская клиническая больнии и имени политического и общественного деятеля Ю.Ф.Горячева; адрес: Российская Фе дераиия, 432011, г. Ульяновск, ул. Радищева, д. 42; тел.: +7(842)2440905; e-mail: odkb@таil.ru

Козлова Елена Александровна, Детская краевая клиническая больнииа им. А.К. Пиотровича; адрес: Российская Федеращия, 680003, г. Хабаровск, ул. Прогрессивная, д. 6 mел.: +7(421)2910448; e-mail: dkkb@dkkb.medkhv.ru

Сикора Наталья Владимировна, Перинатальный иентр; адрес: Российская Федера иия, 680028, г. Хабаровск, ул. Истомина, д. 85; тел.: +7(421)2454156;e-mail: perinatalcenter@ rambler.ru

Молчанова Ольга Викторовна, Институт повыщения квалификащии специалистов здравоохранения; адрес: Российская Федераиия, 680009, г. Хабаровск, ул. Краснодарская, д. 9; тел.: +7(421)2728715; e-mail: rec@ipksz.khv.ru

Саиук Наталья Анатольевна, Нижневартовская окружная клиническая детская больница; адрес: Российская Федерация, 628609, г. Нижневартовск, ул. Северная, д. 30; meл.: +7(346)6492651; e-mail:Zavpulmo@odbhmao.ru

Ревель-Муроз Наталья Петровна, к.м.н., Челябинская областная клиническая больнииа; Российская Федерация, 454048, г. Челябинск, ул. Воровского, д. 70; тел.: +7(351)7493913; e-mail: chelokb@mail.ru 
Каримова Ирина Петровна, к.м.н., Челябинская областная детская клиниче ская больница; адрес: Российская Федераиия, 454087, г. Челябинск, ул. Блюхера, д. 42А тел.: +7(351)2328080; e-mail: info_odkb74@mail.ru

Голубиова Ольга Игоревна, Республиканская детская клиническая больница; адрес: Российская Федеращия, 428003, г. Чебоксары, ул. Федора Гладкова, д. 27; тел.: +7(835)2550126; e-mail:vakcina2007@mail.ru

Павлов Петр Иванович, Республиканская клиническая больнииа; адрес: Российская Федеращия, 428018, 2. Чебоксары, ул. Московский пр., д. 9; тел.: +7(835)2581611; e-mail: rkb@ med.cap.ru

Ашерова Ирина Карловна, к.м.н., Детская клиническая больница №1; адрес: Российская федерация, 150003, г. Ярославль, ул. Ленина пр., д. 12/76; тел.: +7(485)2305163; e-mail:dkblyar@yandex.ru

Зильбер Илья Ефимович, Клиническая больнииа №2; адрес: Российская Федерация 150010, г. Ярославль, ул. Попова, д. 24; mел.: +7(485)2465092; e-mail: info@kb2yar.ru

\section{Author information}

Nika V. Petrova, Dr.Biol.Sci., Research Center for Medical Genetics; Address: 1, Moskvorechje str., Moscow, Russian Federation 115522; Phone: +7(499)3206090; e-mail: npetrova63@mail.ru

Elena I. Kondratyeva, Dr.Med.Sci., Professor, Research Center for Medical Genetics; Address: 1 Moskvorechje str., Moscow, Russian Federation 115522; Phone: $+7(495) 5873366,+7(916) 2553385$; e-mail:elenafpk@mail.ru

Aleksandr V. Polyakov, Dr.Biol.Sci., Professor, Research Center for Medical Genetics; Address: 1 Moskvorechje str., Moscow, Russian Federation 115522; Phone: +7(499)6129846; e-mail: polyakov@ med-gen.ru

Tatyana E. Ivaschenko, Dr.Biol.Sci., Professor, Research Institute of Obstetrics, Gynecolog and Reproductive Medicine D.O. Ott; Address: 3, Mendeleevskaya liniya, St. Petersburg, Russian Federation 199034; Phone: +7(812)3289809; e-mail: tivashchenko2011@mail.ru

Aleksandr E. Pavlov, Parseq Lab; Address: 74A, Doroga v Kamenku, St. Petersburg, Russian Federation, 197350; Phone: +7(812)2431190; e-mail: apavlov@sequoiag.com

Rena A. Zinchenko, Dr.Med.Sci., Professor, Research Center for Medical Genetics; Address: 1 Moskvorechje str., Moscow, Russian Federation 115522; Professor, Moscow Regional Research and Clinical Institute; 61/2, Schepkina str., Moscow, Russian Federation, 129110; Phone: +7 (499)3241224; e-mail: renazinchenko@mail.ru

Evgeniy K. Ginter, Dr.Biol.Sci., Professor, Academician RAS, Research Center for Medical Genetics; Address: 1, Moskvorechje str., Moscow, Russian Federation 115522; Phone: $+7(499) 6120037$ e-mail:mgnc@med-gen.ru

Olga N. Odinokova, Cand.Med.Sci., Tomsk National Research Medical Center; Address: 3 Moskovskiy trakt str., Tomsk, Russian Federation, 634009; Phone: +7(382)2515681; e-mail: olga. odinokova@medgenetics.ru

Lyudmila P. Nazarenko, Dr.Med.Sci., Professor, Tomsk National Research Medical Center; Address: 3, Moskovskiy trakt str., Tomsk, Russian Federation, 634009; Phone: $+7(382) 2535683$ e-mail: ludmila.nazarenko@medgenetics.ru

Nikolay I. Kapranov, Dr.Med.Sci., Professor, Research Center for Medical Genetics, Address: 1, Moskvorechje str., Moscow, Russian Federation 115522; Phone: +7(495)5873366, e-mail:84955873366@mail.ru

Elena L. Amelina, Cand.Med.Sci., Research Institute of Pulmonology, FMBA of Russia Address: 32/4, 11 Parkovaya str., Moscow, Russian Federation 105077; Phone: +7(499)7800806; e-mail:eamelina@mail.ru

Marina A. Starinova, Research Center for Medical Genetics; Address: 1, Moskvorechje str. Moscow, Russian Federation 115522; Phone: +7(495)5873366; e-mail: registrycfrf@gmail.com Sergey I. Kutsev, Dr.Med.Sci., Professor, Corresponding Member of RAS, Research Center for Medical Genetics; Address: 1, Moskvorechje str., Moscow, Russian Federation 115522; Phone: +7(499)6120037; e-mail: mgnc@med-gen.ru

Vera L. Izhevskaya, Dr.Med.Sci., Research Center for Medical Genetics; Address: 1, Moskvorechje str., Moscow, Russian Federation 115522; Phone: +7(499)3241534; e-mail: izhevskaya@med-gen.ru

Olga V. Kondratenko, Dr.Med.Sci., Clinics of Samara State Medical University, Addres: 165B, Karl Marx Prospekt str., Samara, Russian Federation, 443079; Phone: +7(846)2648305, -mail: baclab-samara@yandex.ru

Elena A. Boychenko, Samara city children's clinical hospital № 1 named after N. N. Ivanova; Address: 165A, Karl Marx Prospekt str., Samara, Russian Federation, 443079; Phone: +7(846)2500755; e-mail: mail@1dgkb.ru

Andrey V. Kozlov, Clinics of Samara State Medical University, Address: 165B, Karl Marx Prospekt str., Samara, Russian Federation, 443079; Phone: +7(846)2648305; e-mail: baclab-samara@ yandex.ru

Evgeniya V. Boytsova, Dr.Med.Sci., Professor, St. Petersburg State Pediatric Medical University; Address: 2, Litovskaya str, St. Petersburg, Russian Federation, 194100; Phone: $+7(812) 2950871$; e-mail: Aleks-Shabalov2007@yandex.ru.

Tatyana E. Gembitskaya, Dr.Med.Sci., Professor, Pavlov First Saint Petersburg State Medical University; Address: 6-8, Lev Tolstoy str., St. Petersburg, Russian Federation, 197022 Phone: +7(812)3386625; e-mail: mukoviscidoz_otd@mail.ru

Darya M. Moskvina, Pavlov First Saint Petersburg State Medical University; Address: 12, Rentgena str., St. Petersburg, Russian Federation, 197022; Phone: +7(812)5425362, e-mail: mosquina.daria@yandex.ru

Tatyana A. Stepanenko, Cand.Med.Sci., City General Hospital №2; Address: 5, Uchebnyy pereulok str., St. Petersburg, Russian Federation, 194354; Phone: +7(812)3389486; e-mail: b2@zdrav. spb.ru

Tatyana A. Filippova, City General Hospital №2; Address: 5, Uchebnyy pereulok str., St. Petersburg, Russian Federation, 194354; Phone: +7(812)3389331; e-mail: b2@zdrav.spb.ru

Lyudmila E. Konovalova, Children's Clinical Hospital; Address: 6, Komsomola str., St. Petersburg, Russian Federation, 195009; Phone: +7(812)5420191; e-mail: dkb@lodkb.ru

Victoriya R. Makhmutova, City General Hospital №2; Address: 5, Uchebnyy pereulok str., St. Petersburg, Russian Federation, 194354; Phone: +7(812)3389331; e-mail: b2@zdrav.spb.ru

Aleksandr V. Orlov, Children's City Hospital of St. Olga; Address: 2, Zemledelcheskaya str., St. Petersburg, Russian Federation, 194156; Phone: +7(812)2956998; e-mail: pulmonology3@hotmail. com

Aleksandr A. Pashkevich, Children's City Hospital of St. Olga; Address: 2, Zemledelcheskaya str., St. Petersburg, Russian Federation, 194156; Phone: +7(812)2956992; e-mail: pulmonology3@ hotmail.com

Marina I. Nikitina, Children's City Hospital of St. Olga; Address: 2, Zemledelcheskaya str., St. Petersburg, Russian Federation, 194156; Phone: +7(812)2956992; e-mail: pulmonology3@hotmail com

Viktor N. Kovalev, Children's City Hospital of St. Olga; Address: 2, Zemledelcheskaya str., St. Petersburg, Russian Federation, 194156; Phone: +7(812)2956992; e-mail: pulmonology3@hotmail. com

Mariya N. Ignatyeva, Children's City Hospital of St. Olga; Address: 2, Zemledelcheskaya str., St. Petersburg, Russian Federation, 194156; Phone: +7(812)2956992; e-mail: pulmonology3@hotmail.
Oksana A. Ushatskaya Children's City Hospital of St. Olaa: Address: 2, Zemledelcheskaya str., St. Petersburg, Russian Federation, 194156; Phone: +7(812)2956992; e-mail: pulmonology3@ hotmail.com

Taras S. Borisenko, Children's City Hospital of St. Olga; Address: 2, Zemledelcheskaya str., St. Petersburg, Russian Federation, 194156; Phone: +7(812)2956992; e-mail: pulmonology3@hotmail. com

Lyubov A. Antipova, Children's City Hospital of St. Olga; Address: 2, Zemledelcheskava str., St. Petersburg, Russian Federation, 194156; Phone: 77(812)2956992; e-mail: pulmonology3@hotmail.

com Natalya D. Ponomareva, Sverdlovsk Regional Clinical Hospital № 1; Address: 185, Volgogradskaya str., Yekaterinburg, Russian Federation, 620102; Phone: +7(343)3511532; e-mail: office@okb1.ru

Irina P. Shulyak, Regional Children's Clinical Hospital № 1; Address: 32, Serafima Deryabina str., Yekaterinburg, Russian Federation, 620149; Phone: +7(343)2405780; e-mail: odkb-public@ mis66.ru

Olga B. Novikova, Cand.Med.Sci., Smolensk State Medical University; Address: 30, Marshala Koneva str., Smolensk, Russian Federation, 214019; Phone: +7(481)2555494; e-mail: gospedfpk@ smolgmu.ru

Irina L. Alimova, Dr.Med.Sci., Professor, Smolensk State Medical University; Address: 30 Marshala Koneva str, Smolensk, Russian Federation, 214019; Smolensk State Medical University Address: 30, Marshala Koneva str., Smolensk, Russian Federation, 214019; Phone: +7(481)2555494; e-mail: gospedfpk@smolgmu.ru

Ella V. Vodovozova, Cand.Med.Sci., Stavropol State Medical University; Address: 310, Mira str., Stavropol, Russian Federation, 355017; Phone: +7(865)2352331; e-mail: postmaster@stgmu.ru Larisa N. Ledeneva, Cand.Med.Sci., Stavropol State Medical University; Address: 310, Mira str., Stavropol, Russian Federation, 355017; Phone: + 7(865)2352331; e-mail: postmaster@stgmu.ru
Elena A. Enina, Cand.Med.Sci., Regional Children's Clinical Hospital; Address: 3, Semashko str., Russian Federation, 355029; Phone: +7(865)2357338; e-mail: kdkb@skkdkb.ru

Tatyana A. Ponomareva, Stavropol State Medical University; Address: 310, Mira str., Stavropol, Russian Federation, 355017; Phone: +7(865)2352331; e-mail: postmaster@stgmu.ru

Inna S. Oganesyan, Regional Children's Clinical Hospital; Address: 3, Semashko str., Russian Federation, 355029; Phone: +7(865)2357338; e-mail: kdkb@skkdkb.ru

Natalya A. Kanukova, Stavropol Regional Clinical Consulting and Diagnostic Center; Address: 304, Lenina str., Stavropol, Russian Federation, 355017; Phone: +7(865)2951951; e-mail: skkdc@ skkdc.r

Mery E. Aleksanyan, Tambov Regional Children's Clinical Hospital; Address: 80, Ryleeva str. Tambov, Russian Federation, 392000; Phone: +7(475)2580435; e-mail: post@odb.tambov.gov.ru

Elena V. Zakurnaeva, Tambov Regional Children's Clinical Hospital; Address: 80, Ryleeva str.

Tambov, Russian Federation, 392000; Phone: +7(475)2580435; e-mail: post@odb.tambov.gov.ru

Margarita N. Filimonova, Tomsk National Research Medical Center; Address: 3, Moskovskiy

trakt str., Tomsk, Russian Federation, 634009; Phone: +7(382)2533625; e-mail: margarita. flimonova@medgenetics.ru

Irina I. Smirnova, Tomsk National Research Medical Center; Address: 3, Moskovskiy trakt str. Tomsk, Russian Federation, 634009; Phone: +7(382) 2530537; e-mail: genetics@tnimc.ru

Valeriya V. Mukhacheva, Tomsk National Research Medical Center; Address: 3, Moskovskiy trakt str., Tomsk, Russian Federation, 634009; Phone: +7(3822)530537; e-mail: genetics@tnimc.ru Yuliya E. Kalinina, Tula Regional Children's Clinical Hospital; Address: 39, Bondarenko str. Tula, Russian Federation, 300010; Phone: +7(4872)480130; e-mail: guz.tdokb@tularegion.ru Irina A. Bulatova, Regional Clinical Hospital №1; Address: 55/4, Kotovskogo str., Tyumen, Russian Federation, 625023; Phone: +7(345)2560010; e-mail: tmn560010@gmail.com

Natalya V. Tryastsina, Regional Clinical Hospital №1; Address: 55/4, Kotovskogo str., Tyumen, Russian Federation, 625023; Phone: +7(345)2560010; e-mail: tmn560010@gmail.com

Tatyana V. Simanova, Republican Children's Clinical Hospital; Address: 79, Lenina str., Izhevsk, Russian Federation, 426009; Phone: +7(341)2330363; e-mail: rdkb-priem@mail.ru

Elena V. Osipova, Cand.Med.Sci., First Republican Clinical Hospital; Address: 57, Votkinskoye shosse str., Izhevsk, Russian Federation, 426000; Phone: +7(341)2468771; e-mail: main@rkb1.udm.

Oksana I. Starodubtseva, First Republican Clinical Hospital; Address: 57, Votkinskoye shosse str., Izhevsk, Russian Federation, 426000; Phone:+7(341)2204700; e-mail: main@rkb1.udm.ru

Nataliva P. Muraleva, Republican Children's Clinical Hospital; Address: 79, Lenina str., Izhevsk, Russian Federation, 426009; Phone: +7(341)2330363; e-mail: rdkb-priem@mail.ru

Tatyana A. Kochergina, First Republican Clinical Hospital; Address: 57, Votkinskoye shosse str. Izhevsk, Russian Federation, 426000; Phone: +7(341)2465483; e-mail: main@rkb1.udm.ru

Elena V. Gogoleva, Republican Children's Clinical Hospital; Address: 79, Lenina str., Izhevsk, Russian Federation, 426009; Phone: +7(341)2330363; e-mail: rdkb-priem@mail.ru

Tatyana A. Gubareva, Goryachev Ulyanovsk Regional Children's Clinical Hospital; Address: 42 Radishcheva str., Ulyanovsk, Russian Federation, 432011; Phone: +7(842)2440905; e-mail: odkb@ mail.ru

Elena A. Kozlova, Piotrovich Children's Regional Clinical Hospital; Address: 6, Progressivnaya str., Khabarovsk, Russian Federation, 68000; Phone: +7(421)2910448; e-mail: dkkb@dkkb.medkhv.ru Natalya V. Sikora, Perinatal Center; Address: 85, Istomina str., Khabarovsk, Russian Federation, 680028; Phone: +7(421)2454156; e-mail: perinatalcenter@rambler.ru

Olga V. Molchanova, Institute for Advanced Studies of Health Professionals; Address: 9. Krasnodarskaya str., Khabarovsk, Russian Federation, 680009; Phone: +7(421)2728715; e-mail: rec@ipksz.khv.ru

Natalya A. Satsuk, Nizhnevartovsk Regional Clinical Children's Hospital; Address: 30, Severnaya str., Nizhnevartovsk, Russian Federation, 628609; Phone: +7(346)6492651; e-mail:Zavpulmo@odbhmao.ru

Natalya P. Revel-Muroz, Cand.Med.Sci., Chelyabinsk Regional Clinical Hospital; Address: 70 Vorovskogo str., Chelyabinsk, Russian Federation, 454048; Phone: +7(351)7493913; e-mail: chelokb@ mail.ru

Irina P. Karimova, Cand.Med.Sci., Chelyabinsk Regional Children's Clinical Hospital; Address: 42A, Blukhera str., Chelyabinsk, Russian Federation, 454087; Phone: +7(351)2328080; e-mail: info odkb74@mail.ru

Olga I. Golubtsova, Republican Children's Clinical Hospital; Address: 27, Fedora Gladkova str., Cheboksary, Russian Federation, 428003; Phone: +7(835)2550126; e-mail: vakcina2007@mail.ru Petr I. Pavlov, Republican Clinical Hospital; Address: 9, Moskovskiy pereulok str., Cheboksary Russian Federation, 428018; Phone: +7(835)2581611; e-mail: rkb@med.cap.ru

Irina K. Asherova, Cand.Med.Sci., Children's Clinical Hospital №1; Address: 12/76, Lenina proezd str., Yaroslavl, Russian Federation, 150003; Phone: +7(485)2305163; e-mail: dkblyar@ yandex.ru

Ilya E. Zilber, Clinical Hospital №2; Address: 24, Popova str., Yaroslavl, Russian Federation, 150010; Phone: +7(485)2465092; e-mail: info@kb2yar.ru

Поступила 30.12 .2018 2.

Принята к печати 13.02.2019

Received 30 December 2018

Accepted for publication 13 February 2019 